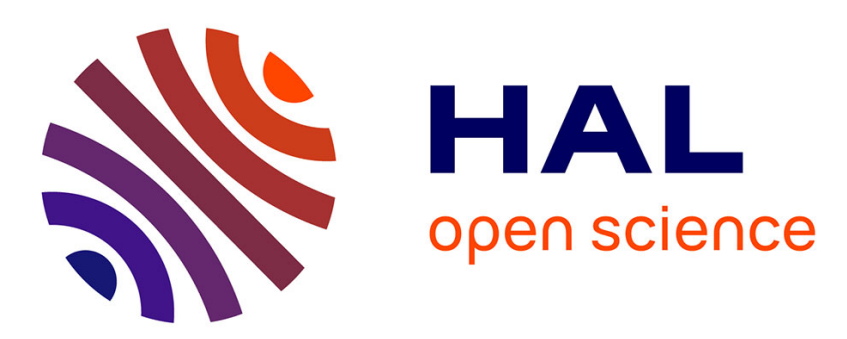

\title{
A REVIEW OF FRACTURE TOUGHNESS TRANSFERABILITY WITH CONSTRAINT AND STRESS GRADIENT
}

G Pluvinage, Julien Capelle, M Hadj Méliani

\section{- To cite this version:}

G Pluvinage, Julien Capelle, M Hadj Méliani. A REVIEW OF FRACTURE TOUGHNESS TRANSFERABILITY WITH CONSTRAINT AND STRESS GRADIENT. Fatigue and Fracture of Engineering Materials and Structures, 2014, 37 (11), pp.1165-1185. 10.1111/ffe.12232 . hal-02972573

\section{HAL Id: hal-02972573 \\ https://hal.science/hal-02972573}

Submitted on 20 Oct 2020

HAL is a multi-disciplinary open access archive for the deposit and dissemination of scientific research documents, whether they are published or not. The documents may come from teaching and research institutions in France or abroad, or from public or private research centers.
L'archive ouverte pluridisciplinaire HAL, est destinée au dépôt et à la diffusion de documents scientifiques de niveau recherche, publiés ou non, émanant des établissements d'enseignement et de recherche français ou étrangers, des laboratoires publics ou privés. 


\title{
A REVIEW OF FRACTURE TOUGHNESS TRANSFERABILITY \\ WITH CONSTRAINT AND STRESS GRADIENT
}

\section{G. Pluvinage, J. Capelle, and M. Hadj Méliani}

\begin{abstract}
In this review paper, only constraint and stress gradient approaches to transferability of fracture toughness are examined.

The different constraint parameters are defined and discussed and one example is given in each case. Factors that are influenced the constraint are studied. Special attention is given to the actual trends is to use the plastic constraint in the Material Failure Master Curve (MFMC) and the Material Transition Temperature Master Curve (MTTMC). The paper also deals with the influence of $\mathrm{T}$ stress on the crack path and out-of-plane constraint on the influence of thickness on fracture toughness.
\end{abstract}

The uses of plasticity with gradient and the relative stress gradient in local fracture approaches are also examined.

Key words: constraint, relative stress gradient, T stress, Q parameter

\section{NOMENCLATURE}

A constant

$\mathrm{A}_{\mathrm{i}}$ William's stress distribution parameters

$\widehat{A_{l}}$ HRR stress distribution parameters

$A_{P}$ Constraint parameter

$A_{p, c}$ current plastic zone area

$\mathrm{A}_{\mathrm{p}, \mathrm{ssy}}$ reference plastic zone area

$\mathrm{A}_{\varepsilon p, c}$ area surrounded by the equivalent plastic strain

$\mathrm{A}_{\varepsilon p \text {,ref }}$ reference area surrounded by the $\left(\varepsilon_{\mathrm{p}}\right)$ isolines

$\mathrm{B}$ thickness

$\mathrm{B}_{0}, \mathrm{~B}_{1}, \mathrm{~B}_{2}$ and $\mathrm{B}_{3}$ constants

$\mathrm{D}$ pipe diameter

$\mathrm{D}_{0}$ length

E Young's modulus

F geometry correction factor

$\mathrm{G}$ shearing modulus

$\mathrm{G}_{\mathrm{c}}$ fracture toughness

I complex function of eigenvalues

$\mathrm{I}_{\mathrm{n}}$ dimensionless integration constant

$\mathrm{J}$ path integral

$\mathrm{J}_{\mathrm{C}}$ fracture toughness

$\mathrm{J}_{\mathrm{Ic}}$ fracture toughness plane strain conditions

$\mathrm{J}_{\text {ref }}$ reference fracture toughness

$\mathrm{K}_{\mathrm{Ic}}$ fracture toughness for plane strain conditions

$\mathrm{K}_{\mathrm{Jc}}$ fracture toughness

$\mathrm{K}_{\mathrm{Iz}, \mathrm{c}}$ three-dimensional fracture toughness in pure mode I

$\mathrm{K}_{0}$ lower bound of the notch fracture toughness 
$\mathrm{K}_{\rho, \mathrm{c}}$ notch fracture toughness

$K_{\rho, c}^{0}$ fracture toughness corresponding to $T_{e f, c}=0$

L plastic constraint factor

$\mathrm{N}$ strain hardening exponent

$\mathrm{P}_{\text {ref }}$ reference property

$\mathrm{P}_{\text {struct }}$ structure material property

$P$ transferability parameter

$\mathrm{Q}$ the $\mathrm{Q}$ parameter

Rm ultimate strength

$\mathrm{T}$ stress the $\mathrm{T}$ stress

$\mathrm{T}_{\mathrm{ef}, \mathrm{c}}$ value at critical load

$\mathrm{T}_{0}$ reference temperature

$T_{t . T e f, c=0}$ transition temperature corresponding to a constraint equal to zero

$T_{0, \text { ref }}$ reference temperature for a reference constraint

$T_{0}^{C I}$ constraint indexing master curve reference temperature

$\bar{T}$ non - dimensional function

$\mathrm{T}_{\mathrm{z}}$ triaxial stress constraint

$\mathrm{U}_{\mathrm{c}}$ fracture energy

$\mathrm{X}_{\mathrm{ef}}$ effective distance

$\mathrm{X}_{\mathrm{c} . \text { characteristic distance }}$

$X_{e f, c}$ critical effective distance

$X_{\beta m a x, c}$. distance where the triaxiality is maximum

$\mathrm{Y}_{\text {ref }}$ constraint parameter for a reference case

$\mathrm{a}_{2}, \mathrm{~b}_{2}$ and $\mathrm{c}_{2}$ constant

$\mathrm{b}_{\mathrm{m}}$ Basquin' exponent

c constant

$\mathrm{c}_{1}$ and $\mathrm{c}_{2}$ constants

d constant

$c_{s}$ weight function skew factor and polar fu

$f(\theta)$ polar function

$\mathrm{k}_{\mathrm{t}}$ stress concentration factor

1 reference length

$1_{\mathrm{ch}}$ characteristic length $\mathrm{x}$ max where opening stress is maximal

$\overline{r_{p}}$ mean radius of the crack-tip plastic zone

$\mathrm{r}_{\mathrm{y}}$ radius of the elastic boundary

$r^{*}$ specimen radius

$t$ and s exponent

$\mathrm{Z}_{\mathrm{B}}$ relative thickness

$\alpha$ coefficient of the Ramberg-Osgood Law

$\beta$ stress triaxiality

$\beta_{\max , c}$ maximum critical stress triaxiality

$\beta_{e f, c}$ effective critical stress triaxiality

$\chi$ relative stress gradient

$\varepsilon_{0}$ strain associated to the reference stress

epl,eq the plastic equivalent strain 
$\phi$ rotation angle.

$\gamma *$ constant

$\gamma$ shearing strain

$\eta$ parameter for the proportionality

$\varphi$ constraint parameter

$\theta$ polar angle

$\theta^{*}$ bifurcation direction

$\lambda$ scale factor

$v$ Poisson' ratio,

$\sigma_{g, c}$ critical gross stress

$\sigma_{\text {eq }}$ equivalent Von Mises stress

$\sigma_{0}$ reference stress

$\sigma_{\mathrm{VM}}$ Von Mises stress

$\sigma_{\mathrm{h}}$ hydrostatic stress

$\sigma_{N}^{c}$ critical net stress

$\sigma_{\mathrm{N}}$ net stress

$\widetilde{\sigma_{l j}} \widetilde{\varepsilon_{l j}}$ eigenvalues

$\sigma_{\mathrm{VM}}$ Von Mises equivalent stress

$\sigma$ 'f, Basquin's coefficient

$\hat{\sigma}_{D}$ actual endurance limit

$\hat{\sigma}_{D N}$ real fatigue limit

$\tau_{\mathrm{y}}$ is the shearing yield stress

$\tau_{y, a p}$ is the apparent yield stress in torsion

$\Delta \mathrm{T}^{*}$ shift of the test temperature

$\check{\chi}$ relative maximum stress gradient

$\Delta \sigma$ applied stress range

$\Theta$ biaxiality ratio

\section{1) INTRODUCTION}

Mechanical properties are not intrinsic to material but depend on geometrical factors such as the specimen geometry, thickness, surface roughness and length, defect geometry such as the relative length, radius, or opening angle, loading mode, and environment. Sinclair and Chambers [1] have carried out fracture tests on brittle materials in plane strain conditions and on ductile materials in plane stress conditions and have found that the classical linear fracture mechanics cannot predict fracture stress and is over-conservative.

If we consider two specimens that are geometrically identical but with different size, where the smallest is the model " $\mathrm{m}$ " and the second is the prototype " $p$ ", the ratio of the geometrical dimensions including the crack length is equal to the scale factor $\lambda$. 


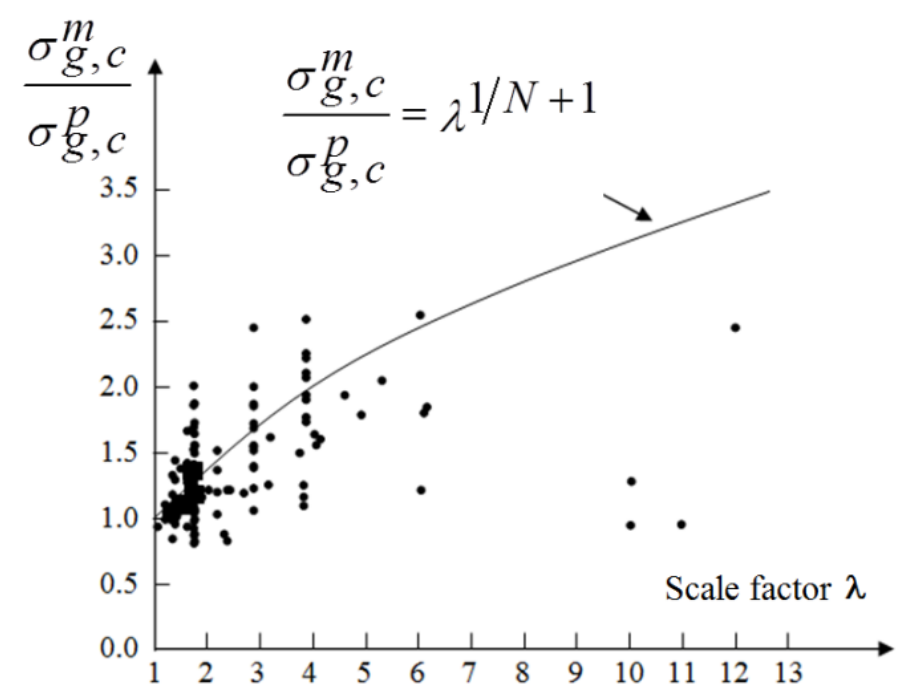

Fig. 1: Scale effects on ductile fracture in plane stress. Experiments by Sinclair and Chambers $[1]$.

For brittle material, if we assume that fracture toughness is intrinsic to material, the ratio of critical gross stress $\sigma_{g, c}$ is given by the following scaling law:

$$
\frac{\sigma_{g, c}^{m}}{\sigma_{g, c}^{p}}=\sqrt{\lambda}
$$

For ductile material this ratio is given by:

$$
\frac{\sigma_{g, c}^{m}}{\sigma_{g, c}^{p}}=\lambda^{1 / N+1}
$$

where $\mathrm{N}$ is the strain hardening exponent of the Ramberg-Osgood strain-stress law.

Material properties available from data banks are therefore to be considered as reference material properties, as results of from standard tests. To use these reference properties for a structure and component which differ in terms of geometry and loading mode, a correction needs to be made, which is called transferability.

The properties to be used in a structure $\mathrm{P}_{\text {struct }}$ are deduced from the reference properties $\mathrm{P}_{\text {ref }}$ and the transferability function $\mathrm{f}(\mathrm{p})$, where $\mathrm{p}$ is the transferability parameter.

$$
\mathrm{P}_{\text {struct }}=\mathrm{P}_{\text {ref. }} \mathrm{f}(\mathrm{p})
$$

Evidence of the scale effect was first pointed out by Leonardo da Vinci (1452-1519), and in the sixteenth century Galileo Galilei said that "from the small to the big is not so simple".

The scale effect is generally represented by models using a characteristic dimension from the structures. For probabilistic approaches [2], the volume $\mathrm{V}$ of the structure, the scale factor $\lambda$ [3], or a characteristic length [3] is used as an adjustable parameter. 
A fractal approach to the scale effect on fracture toughness $G_{c}$ was proposed by Carpinteri et al. [4]. It introduces a characteristic length $1_{\mathrm{ch}}$ which controls the transition from fractal to Euclidian behaviour.

Bazant [5] has developed a scaling law based on an asymptotic and energetic approach. It refers to the critical stress, whose value is ruled by two asymptotic behaviours: plastic collapse without any scale effect and brittle fracture where the scale effect is maximal. These two asymptotes intersect at a length $\mathrm{D}_{0}$, which characterizes the brittle to ductile transition.

For fractures emanating from a defect where fracture mechanics can be applied, the transferability is sometimes treated with the concept of characteristic length or scale factor [6] but more often by using the stress constraint or the relative stress gradient. These transferability parameters emanate from the defect tip distribution (notch or crack). If we compare the stress distribution obtained in a reference situation (generally small scale yielding) with another general one, the stress distribution is modified in two ways: there is a shift of the stress distribution and a small rotation. These modifications of the stress distribution are considered as transferability problems. The shift of the stress distribution is introduced into the plastic constraint, which is used as the transferability parameter. In the literature, we can note the following constraint parameters: the plastic constraint factor L [7], the stress triaxiality $\beta$ [8], the $Q$ parameter [9], T stress [10], and $A_{2}$ [11].

The rotation of the defect tip distribution is also less often used as a transferability parameter. The following parameters can be used: the strain gradient plasticity [12], the defect tip relative stress gradient [13], or the relative stress gradient [14].

Today, there is no proposed approach combining these two aspects of the modification of the stress distribution with geometrical or loading mode parameters.

In this review paper, only constraint and stress gradient approaches to transferability are examined. For the characteristic length approaches, the attention is focused instead on the scale effects [15].

The different constraint parameters are defined and discussed and one example is given in each case. Factors that influence of constraint are studied. Special attention is given to the plastic constraint in the Material Failure Master Curve (MFMC) and the Transition Temperature Master Curve (TTMC). The paper also deals with the influence of $\mathrm{T}$ stress on the crack path and the influence of thickness on fracture toughness with the out-of -plane constraint.

The use of plasticity with gradient and the relative stress gradient in local fracture approaches is also examined.

\section{CONSTRAINT AND RELATIVE STRESS GRADIENT AT DEFECT TIP}

Constraint is considered as a modification of the defect tip distribution under the effects of specimen or defect geometries or loading mode. Different constraint parameters are defined and associated with the defect type or stress-strain behaviour.

\section{Singular elastic stress distribution}

For a notch with infinite acuity, Williams [16] has given a solution for elastic stress distribution as the following series: 


$$
\sigma_{y y}=\frac{A_{I}}{\sqrt{r}}+A_{2}+A_{3} \sqrt{r}+A_{4} r+A_{5} \sqrt{r^{3}}+\ldots
$$

For a crack, Larson et al. [17] have suggested describing the elastic stress field at the crack tip by three terms and introduce for the first time the $\mathrm{T}$ term as the second one of the series:

$\sigma_{i j}=\frac{K_{i j}}{\sqrt{2 \pi r}} f_{i j}(\theta)+T \delta_{1 i} \delta_{l j}+\mathrm{O}(\mathrm{vr})$

Therefore, ideally $\mathrm{T}$ stress is a constant stress which acts along the crack direction and shifts the opening stress distribution according to the sign of this stress. For stress distribution emanating from a blunted crack or notch, T stress is not constant along the ligament. This leads to consider a conventional value defined as the effective $\mathrm{T}$ stress.

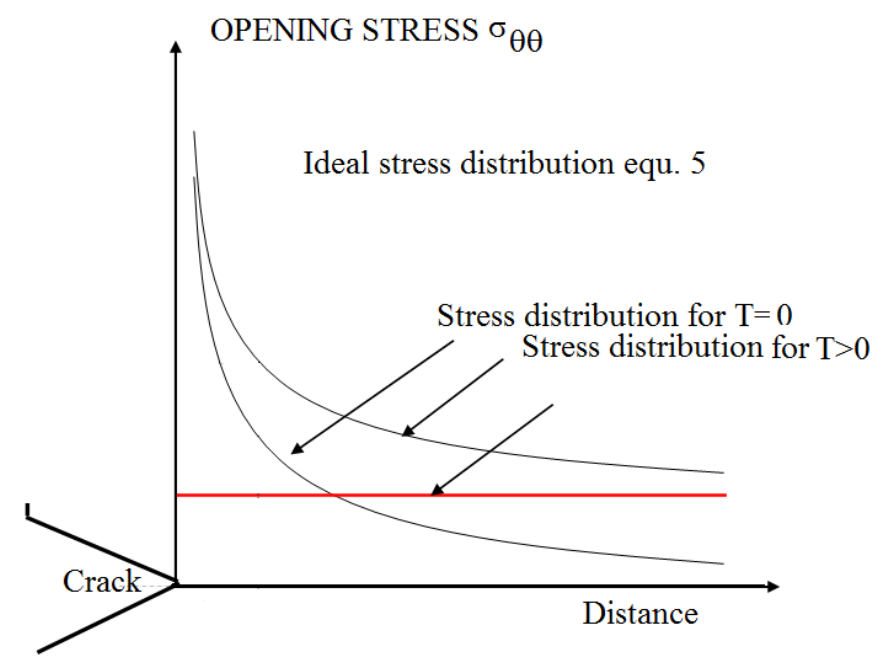

Figure 2 : Ideal T stress distribution and shift of opening stress distribution by T stress.

\section{Singular elastic-plastic stress distribution}

The power-law expansion of the elastic-plastic HRR [18] field if higher-order singular or non-singular terms are considered, is represented by:

$\sigma_{i j}(r, \theta)=\hat{A}_{1}\left[\left(\frac{r}{l}\right)^{s 1} \cdot f_{i j}^{(1)}(\theta)+\hat{A}_{2}\left(\frac{r}{l}\right)^{s 2} \cdot f_{i j}^{(2)}(\theta)+\hat{A}_{2}{ }^{2}\left(\frac{r}{l}\right)^{2 s 2-s 1} \cdot f_{i j}^{(3)}(\theta)\right]+\ldots$

with $\mathrm{s}_{1}=-1 /(\mathrm{N}+1)$ and $\widehat{A_{1}} \sim \mathrm{J}^{1 /(\mathrm{N}+1)}$, where $\mathrm{N}$ is the hardening exponent according to the Ramberg-Osgood constitutive equation, $\mathrm{s}_{2}$ is the exponent of the second singular or nonsingular term, $\mathrm{J}$ is a path integral, and $\mathrm{l}$ is a reference length.

O'Dowd and Shih [19,20] have simplified this formula. Considering strain hardening exponent values in the range $5 \leq \mathrm{N} \leq 20$, the angular functions $f_{\theta \theta}$ and $f_{r r}$ are equivalent and constant $f_{\theta \theta} \approx f_{r r} \approx$ constant, and the value of $f_{r \theta}$ is negligible when compared with $f_{\theta \theta}\left(f_{\theta \theta}\right.$ $>f_{r \theta}$ ) for $|\theta|<\pi / 2$ The stress field is therefore described by:

$\sigma_{i j}=\left(\frac{J}{B_{0} I_{n} r}\right)^{\frac{1}{n+1}} f_{i j}(\theta, n)+Q\left[\frac{r}{J / \sigma_{0}}\right]^{q} f_{i j}(\theta, n)+\ldots$. 
$\mathrm{B}_{0}$ and $\mathrm{I}_{\mathrm{n}}$ are constants for fixed values of $\theta$ and $n ; \mathrm{q}$ is a parameter close to zero $(\mathrm{q} \approx 0)$; and $\sigma_{0}$ is the reference stress. The $\mathrm{Q}$ parameter is called the amplitude factor of the second-order field or simply $\mathrm{Q}$.

\section{Non-singular elastic and elastic plastic stress distribution}

The opening stress at the notch tip exhibits a more complex distribution. The stress increases until it reaches a maximum, which occurs behind the notch tip at distance $\mathrm{x}_{\max }$. At distance $\mathrm{X}_{\text {ef }}$ (the effective distance), the distribution is governed by a power law with an exponent close to those given by the elastic stress distribution of Williams [16]. In Fig. 3, zone III represents precisely this zone, where the stress distribution exhibits a linear behaviour in the bi-logarithmic diagram and is governed by the notch stress intensity factor. In zone IV, the stress distribution decreases until it reaches the gross stress level. The effective distance $\mathrm{X}_{\mathrm{ef}}$ corresponds to the minimum of the relative stress gradient.

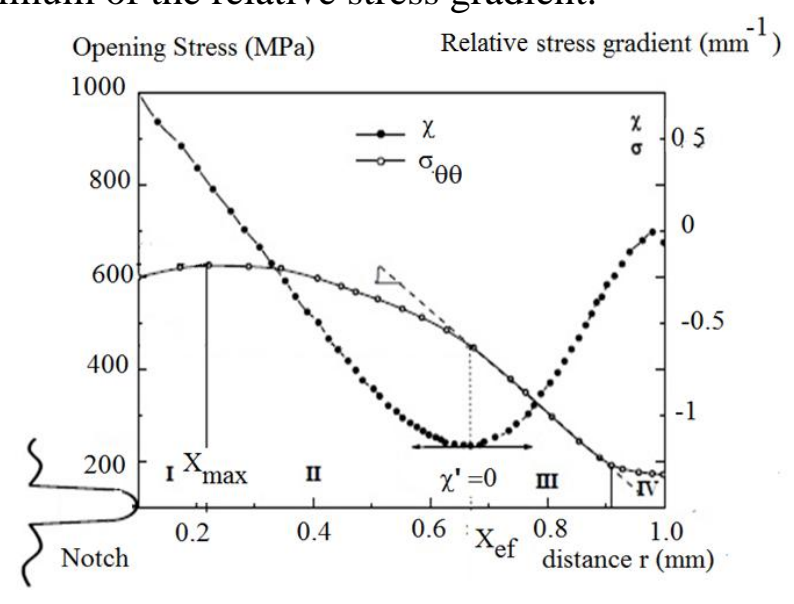

Figure 3 : Elastic-plastic stress distribution and definition of the effective distance from the minimum of the relative stress gradient.

\section{THE DIFFERENT CONSTRAINT PARAMETERS}

To assess the effect of geometry and loading mode on fracture toughness, different twoparameter concepts are applied as $\mathrm{K}-\mathrm{T}$ stress- and $\mathrm{J}-\mathrm{A} 2$-concepts based on a rigorous description of the asymptotic fields as well as the phenomenological $\mathrm{J}-\mathrm{Q}-$ and $\mathrm{J}-\beta$-concepts using the Q-parameter and the stress triaxiality $\beta$ as secondary fracture parameters.

\section{T stress}

The stress distribution ahead of a crack tip depends on the polar angle $\theta$, as we can see in Eq. (2). However for some particular $\theta$ angles, the $\mathrm{T}$ stress is given by particular values of the difference between the opening stress $\sigma_{\mathrm{yy}}$ and the stress parallel to the crack $\sigma_{\mathrm{xx}}$ (see Table 1 ).

Table 1: T stress values according to polar direction $\theta$.

\begin{tabular}{|l|l|l|l|l|}
\hline$\theta=0$ & $\theta= \pm \pi$ & $\theta= \pm \pi / 3$ & $\theta= \pm \pi / 2$ & $\theta= \pm 2 \pi / 3$ \\
\hline$T=\left(\sigma_{\mathrm{xx}}-\sigma_{y y}\right)$ & $T=\sigma_{\mathrm{xx}}$ & $T=\sigma_{\mathrm{xx}}-\sigma_{\mathrm{y} y} / 3$ & $T=\sigma_{\mathrm{xx}}-\sigma_{\mathrm{yy}} / 3$ & $T=\left(\sigma_{\mathrm{xx}}-\sigma_{y y}\right)$ \\
\hline
\end{tabular}

Particularly for $\theta=0$, the $\mathrm{T}$ stress is given by :

$$
T=\left(\sigma_{\mathrm{xx}}-\sigma_{y y}\right)_{\theta=0}
$$


Equation (8) is the basis of the so-called stress difference method, which was proposed by Yang et al. [21]. The stress distribution in the direction $\theta=0$ is generally computed by the finite element method. Chao et al. [22] computed $\sigma_{x x}$ in the direction $\theta=180^{\circ}$ (in the crack back direction) by the finite element method and defined the T stress as the value of $\sigma_{x x}$ in the region where the value is constant. Ayatollahi et al. [23] determined the T stress by using the Displacement Method in the finite element and then obtained a stabilized T stress distribution along the ligament.

T-stress can be measured experimentally using strain with the difference between the normal strains in polar coordinates after a rotation of the angle $\alpha$. From Williams's solution, the strain difference is given by:

$$
\begin{aligned}
E\left(\epsilon_{r r}-\epsilon_{\theta \theta}\right)= & A_{1} r^{-0.5}(1+v) \sin \theta\left[\cos \frac{3 \theta}{2} \sin 2 \alpha-\sin \frac{3 \theta}{2} \cos 2 \alpha\right] \\
+ & 2 A_{2} r^{0}(1+v) \cos 2 \alpha \\
& +A_{3} r^{0.5}(1+v) \sin \theta\left[\sin \frac{\theta}{2} \cos 2 \alpha-\cos \frac{\theta}{2} \cos 2 \alpha\right] \\
& +2 A_{4} r^{1}(1+v)[\cos \theta+\cos 2 \alpha-2 \sin \theta \sin 2 \alpha]
\end{aligned}
$$

Here, E and $v$ are the Young's modulus and Poisson's ratio, respectively, the value of $\mathrm{A}_{1}$ is proportional to the stress intensity factor $\mathrm{K}_{\mathrm{I}}$, and the parameter $\mathrm{A}_{2}$ is proportional to the $\mathrm{T}$ stress. For the angles $\theta= \pm 120^{\circ}$ (MM line of Fig. 4), Eq. (9) can be simplified and leads to the following approximation for small values of $r$ :

$$
\frac{E}{(1+v)}\left(\epsilon_{x x}-\epsilon_{x y y}\right) \sim 2 A_{2}
$$

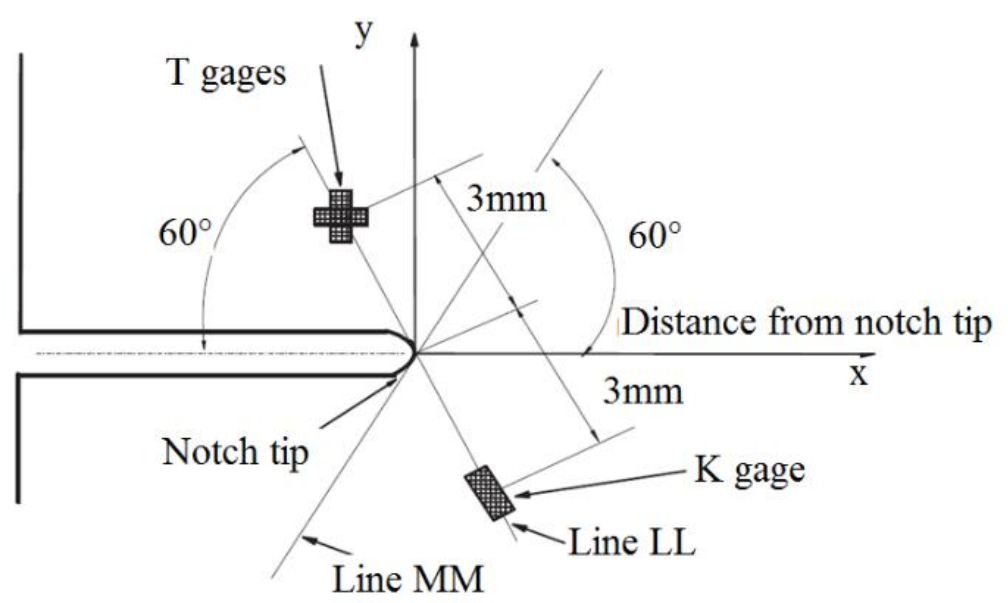

Fig. 4. Experimental determination of T stress using strain gauges [26].

Physically, $\mathrm{T}$ stress is a stress acting parallel to the crack line in the $\mathrm{x}$ direction to the extension of the crack with amplitude proportional to the gross stress. T may be positive (tensile) or negative (compression).

An example of the computed $\mathrm{T}$ stress distribution along the ligament for a Roman tile specimen with a notch is given in Fig. 5. It can be seen that $\mathrm{T}$ is not really constant as it is in 
theory. For short cracks, distribution of the $\boldsymbol{T}$ stress is stabilized after some distance. For long cracks, $T$ increases linearly with the ligament except in a region close to the crack tip. To avoid this dependence of the $\mathrm{T}$ stress on distance, it is attractive to use a conventional definition of the effective $\mathrm{T}$ stress.

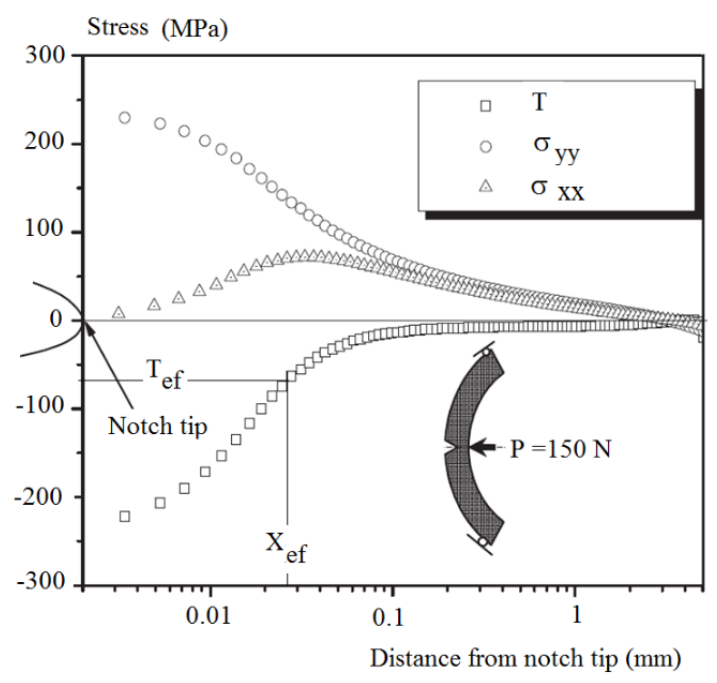

Fig. 5. $\mathrm{T}$ stress evolution with distance for a Roman tile specimen. Values of $\mathrm{T}_{\text {ef }}$ parameter obtained by extrapolation or volumetric methods.

Maleski et al. [27] suggested representing the $T$ stress evolution by a linear relationship with distance $\mathrm{x}$ :

$$
\left.\mathrm{T}(\mathrm{x})=\mathrm{T}_{\mathrm{ef}}+\gamma *(\mathrm{x} / \mathrm{a})\right)
$$

where $\gamma^{*}$ is a constant and a is the crack depth. $\mathrm{T}_{\text {ef }}$ is obtained by extrapolation $x \rightarrow 0$. Using the volumetric method, Hadj Meliani et al. [28] suggested defining the effective $T$ stress as the corresponding value in the $\mathrm{T}$ stress distribution for a distance equal to the effective distance $\mathrm{X}_{\mathrm{ef}}$. Figure 5 gives the $\mathrm{T}$ stress evolution with distance for a Roman tile specimen and the definition of $\mathrm{T}_{\text {ef. }}$. One notes that in this case the values of $\mathrm{T}_{\mathrm{ef}}$ obtained by extrapolation or the volumetric method are relatively close. In the following, the $\mathrm{T}_{\text {ef }}$ parameter obtained from the critical stress distribution is called $\mathrm{T}_{\mathrm{ef}, \mathrm{c}}$.

\section{Q Parameter}

In Eq. (5) the $J$-integral sets the size scale over which high stresses develop while the second parameter, $Q$, quantifies the level of some stress shift at distances of a few CTODS ahead of the crack tip; such a dimension defines the physically relevant length scale of the fracture process zone $\mathrm{X}_{\mathrm{ef}}$.

The constraint has been defined by Dodds et al. [29] using the Q parameter. This parameter is defined as the difference between the opening stress level for a given geometry or loading mode and a reference situation with generally small scale yielding (ssy) divided by the reference

$$
Q=\frac{\sigma_{\sigma \sigma}-\left(\sigma_{\sigma \sigma}\right)_{s s y}}{\sigma_{0}}
$$


O'Dowd and Shih $[19,20]$ showed that $Q$ corresponds effectively to a spatially uniform hydrostatic stress and represents the relative difference between the high triaxiality reference stress field and that of the fracture specimen. $Q$ is defined at a non-dimensional distance of $\sigma_{0}$ $\mathrm{r} / \mathrm{J}=2$. In order to fulfil the condition of a spatially uniform $\mathrm{Q}$, it is necessary that the reference and the studied stress field be homothetic. The following conditions are added for a correct determination of Q:

$$
\operatorname{grad} Q=\frac{Q_{(1)}-Q_{(5)}}{4} \leq 0,1
$$

where $\mathrm{Q}_{(1)}$ and $\mathrm{Q}_{(5)}$ are $\mathrm{Q}$ values determined respectively at the non-dimensional distances 1 and 5.

If the condition given by Eq. (13) is satisfied, the stress distributions corresponding to the small scale yielding and the studied one are homothetic. Here, we considered a local fracture criterion for brittle fracture with two parameters, the critical stress $\sigma_{c}$ and the characteristic distance $\mathrm{X}_{\mathrm{c}}$. The characteristic distance is in this case independent of the stress distribution and is associated with a material characteristiclf we multiply the relationship (16) by $\sqrt{\pi X_{c}}$ :

$$
Q=\frac{\sigma_{y y} \cdot \sqrt{\pi \cdot X_{c}}-\left(\sigma_{y y}\right)_{S S Y} \cdot \sqrt{\pi \cdot X_{c}}}{\sigma_{y} \cdot \sqrt{\pi \cdot X_{c}}}
$$

and multiply again by the geometry correction factor F:

$$
Q=\frac{K_{c}-K_{I c}}{\sigma_{y} \cdot \sqrt{\pi \cdot X_{c}} F}
$$

we can see that in this case $Q$ is simply the relative difference between critical stress intensity factors.

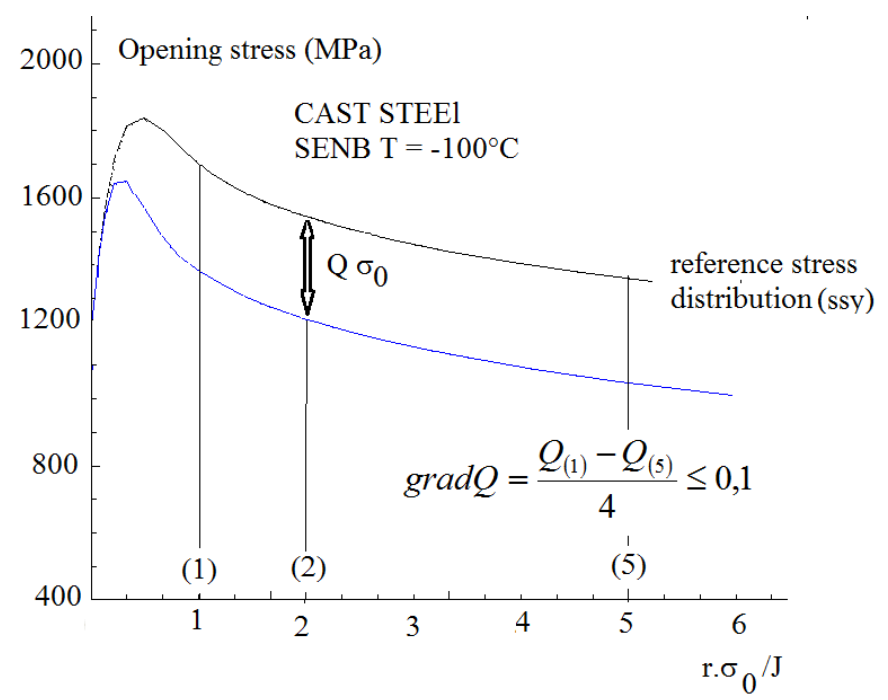

Fig. 6. Definition of Q parameter and validity condition. 


\section{Stress triaxiality}

The stress triaxiality $\beta$ is also used as a measure of the constraint and leads to the twoparameter fracture mechanics approach $\mathrm{K}-\beta$ or $\mathrm{J}-\beta$. Stress triaxiality is chosen as a transferability parameter because ductile fracture is sensitive to this parameter through void growth [30] as well as cleavage stress for brittle fracture [31].

This parameter is defined as the ratio of the hydrostatic stress over the equivalent von Mises stress.

$$
\beta=\frac{\sigma_{h}}{\sigma_{e q, V M}}
$$

where: $\quad \sigma_{h}=\frac{\sigma_{x x}+\sigma_{y y}+\sigma_{z z}}{3}$

and: $\quad \sigma_{e q}=\frac{1}{\sqrt{2}} \sqrt{\left(\sigma_{1}-\sigma_{3}\right)^{2}+\left(\sigma_{1}-\sigma_{2}\right)^{2}+\left(\sigma_{2}-\sigma_{3}\right)^{2}}$

The critical stress triaxiality distribution at the notch tip increases until it reaches a maximum, which for the critical event is called $\beta_{\max , c}$ and corresponds to the distance $X_{\beta \max , c}$. After that, it decreases, then sometimes increases again, and finally falls to zero when the distance is far from the notch tip.

The maximum critical stress triaxiality is sensitive to the notch radius and ligament size. It decreases practically linearly with the notch radius and increases with relative notch depth [32]. It has been noted that the maximum triaxiality always occurs inside the fracture process zone since $X_{\beta_{\max }^{c}, c}$ remains lower than or equal to the critical effective distance $X_{e f, c}$ [32].

With an increase of the relative notch depth, the position of maximum stress triaxiality approaches or reaches the limit of the fracture process zone.

According to [32], the maximum stress triaxiality parameter is not the most suitable constraint parameter to explain the modification of fracture toughness with ligament size or thickness. An improvement has been made using the effective critical stress triaxiality $\beta_{e f, c}$. This parameter is defined as the average value of the critical stress triaxiality over the critical effective distance $X_{e f, c}$.

$$
\beta_{e f, c}=\frac{1}{X_{e f, c}} \int_{0}^{X_{f, c}} \beta(x) d x
$$

\section{Other constraint parameters}

\section{$A_{2}$ and $A_{3}$ parameters}

A three-term asymptotic solution for stresses near the tip of the crack in an elastic-plastic body can be written in the form [33]:

$\frac{\sigma_{i j}}{\sigma_{0}}=\tilde{A}_{1} \bar{r}^{s} f_{i j}^{0}+\tilde{A}_{2} \bar{r}^{t} f_{i j}^{1}+\tilde{A}_{3} \bar{r}^{2 t-s} f_{i j}^{2}$

where $\bar{r}$ is the dimensionless distance: 
$\mathrm{t}$ and $\mathrm{s}$ are exponent, and $\sigma_{0}$ is the reference stress. $f_{i j}^{0}, f_{i j}^{1} a n d f_{i j}^{2}$ are normalized angular functions obtained from the solutions of asymptotic problems. $A_{1}$ and $A_{2}$ are two independent amplitudes found by stress fitting inside the fracture process volume.

$\tilde{A}_{1}=\left(\frac{J}{\alpha \varepsilon_{0} \sigma_{0} I_{n} l}\right)^{-s} s=-\frac{1}{N+1}$

The dimensionless integration constant $\mathrm{I}_{\mathrm{n}}$ depends only on the hardening exponent $\mathrm{n}$ and is independent of other material constants (i.e. reference strain $\varepsilon_{0}$ or stress $\sigma_{0}$, , respectively) and applied loads. L is a characteristic length parameter which can be chosen as the crack length a, the specimen width $\mathrm{W}$, the thickness $\mathrm{B}$, or unity. $\alpha *$ is a parameter of the Ramberg-Osgood law.

$\mathrm{A}_{3}$ depends on $\mathrm{A}_{1}$ and $\mathrm{A}_{2}$ :

$\tilde{A}_{3}=\frac{\tilde{A}_{1}^{2}}{\tilde{A}_{2}}$

$\tilde{A}_{1}$ is related to $\mathrm{J}$, and $\tilde{A}_{2}$ is related and close to $\mathrm{Q}$. The constraint parameter $\tilde{A}_{2}$ is determined as presented by Nikishkov [33] by comparison of the actual radial and circumferential stresses distribution in the specimen and the stresses according to the reference asymptotic field at two points located in the ligament and at $\theta=\pi / 4$, both at a distance of $r=2 \mathrm{~J} / \sigma_{0}$. This procedure is identical to those used for $\mathrm{Q}$ determination.

$\tilde{A}_{3}$ can be used for a three-parameter fracture approach, K-T-A 3 or J-A2-A 3 [34-36].

\section{Plastic constraint factor}

The plastic constraint factor is used for determination of the limit state. The theory of limit analysis appeared in the late 1930s. It constitutes a branch of the theory of plasticity related to an elastic perfectly plastic behaviour. In the mid-1950s a large number of analytical solutions appeared for calculating the ultimate load of beams and shells, leading to more realistic values of the capacity to resist plastic collapse.

The introduction of linear fracture mechanics in the mid-1950s led to consider the risk of brittle fracture governed by the global stress in apparent opposition to the theory of plastic collapse governed by the net stress.

This failure criterion assumes that failure occurs when a critical net stress $\sigma_{N}^{c}$ reaches the ultimate strength $\mathrm{Rm}$. One notes that ductile failure is sensitive to net stress $\sigma_{\mathrm{N}}$ (load divided by the ligament cross-section) while brittle fracture is sensitive to gross stress $\sigma_{\mathrm{g}}$ (load divided by the entire section). The abovementioned criterion needs to be modified to take into account constraints due to geometry and loading mode effects in the following manner:

$$
\sigma_{N}^{c}=L \cdot R m
$$

where $\mathrm{L}$ is the so-called plastic constraint factor. 
Design codes are based on limit analysis to calculate the limit state and incorporate the safety factor through the lower bound of a plot of experimental results.

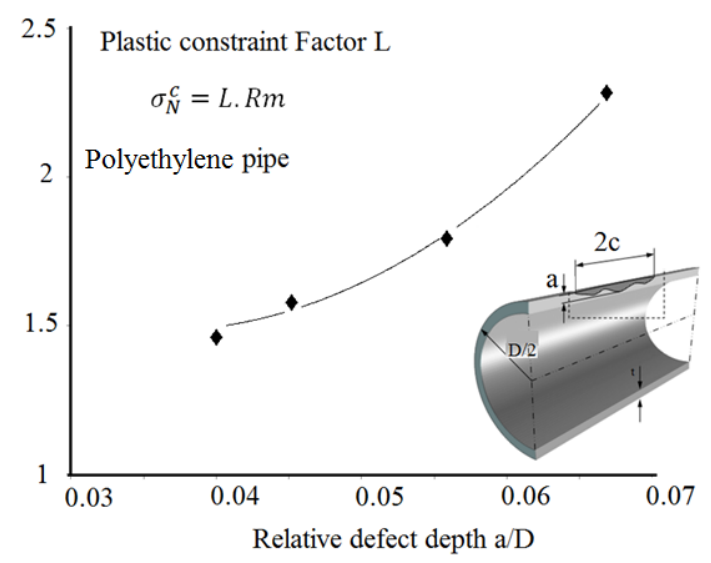

Fig. 7: Evolution of the plastic constraint factor versus the relative defect depth a/D.

Polyethylene pipe.

Figure 7 gives the evolution of the plastic constraint factor in a polyethylene pipe with a semielliptical surface defect. The plastic constraint factor $\mathrm{L}$ is plotted versus the relative defect depth $\mathrm{a} / \mathrm{D}$, where $\mathrm{D}$ is the pipe diameter.

\section{Constraint parameter $\varphi$ or $A_{P}$}

$\mathrm{T}$ stress has a strong influence on the shape and size of the plastic zone. For example, in plane strain the plastic zone has a typical shape of a butterfly wing. For a positive $\mathrm{T}$ stress the wings are oriented in the crack as above direction. If the $\mathrm{T}$ stress is negative, the wings are oriented in the reverse crack extension direction.

This effect is illustrated in Fig. 8, showing the plastic zone ahead of a surface notch defect. This defect is located in a pipe of diameter $\mathrm{D}$ and thickness $\mathrm{B}(\mathrm{B}=8.9 \mathrm{~cm})$. The applied internal pressure is 20 bars.

The size of the plastic zone is also modified because the equivalent stress is modified by the $\mathrm{T}$ stress. If we consider the asymptotic field given by Eq. 3 and $\theta=\pi$, the equivalent von Mises stress $\sigma_{\text {eq }}$ is a function of the ratio $\mathrm{T} / \mathrm{K}_{\mathrm{I}}$ :

$$
\sigma_{e q}(r, \theta=0, v=1 / 3)=\frac{1}{3} \cdot \frac{K_{I}}{\sqrt{2 \pi r}} \cdot \sqrt{\frac{27}{28}+\frac{1}{28} \cdot\left(1+\frac{14 \cdot \sqrt{2 \pi r}^{2}}{K_{I}}\right)}
$$

When $\mathrm{T}$ is negative (specimen in tension), the plastic zone increases compared to the reference case for which $\mathrm{T}=0$. For positive values of $\mathrm{T}$ (double cantilever beam, DCB, or compact tension, $\mathrm{CT}$, specimen), the size of the plastic zone decreases.

Mostafavi et al. [37] have suggested a new constraint parameter $\varphi$ defined as the ratio of the current plastic zone area $A_{p, c}$ and the reference plastic zone area, that is, for a small scale yielding situation $\mathrm{A}_{\mathrm{p}, \mathrm{ssy}}$.

$$
\varphi=\frac{A_{p, c}}{A_{p, s s y}}
$$




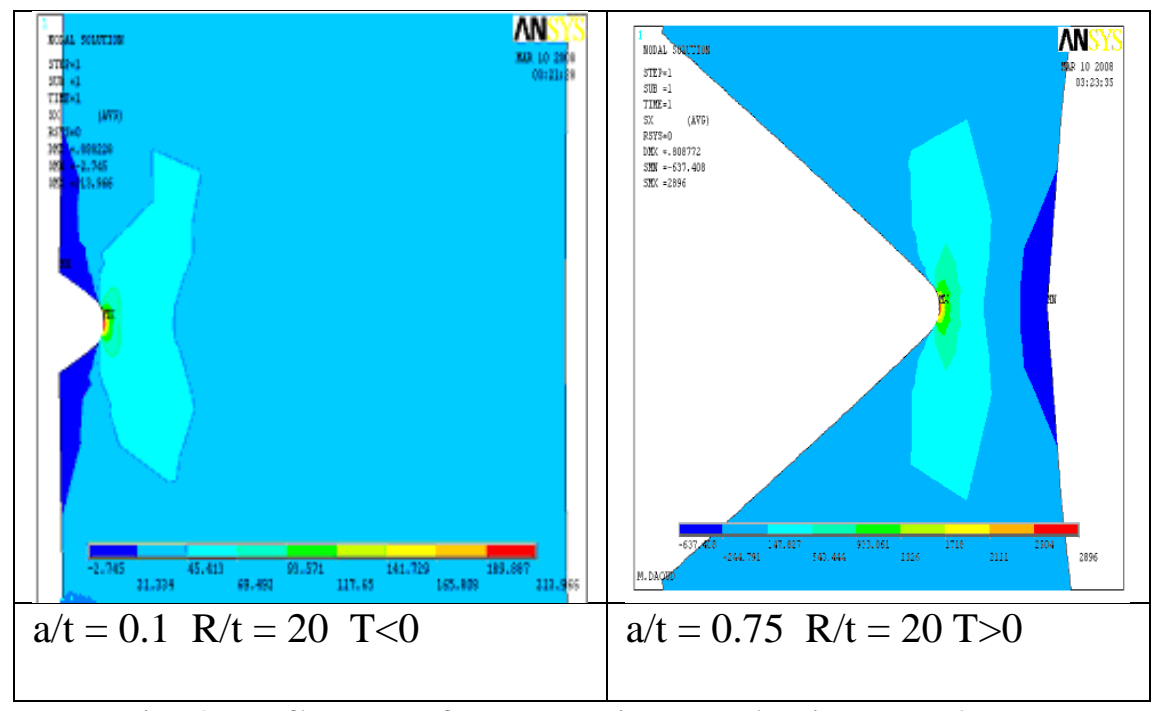

Fig. 8 : Influence of T stress sign on plastic zone shape.

Mostafavi et al. [37] remarked that the constraint parameter $\varphi$ has its limitation in characterizing the constraint at a higher J-integral value for ductile material and suggested that the constraint definition be modified by a new parameter $\mathrm{A}_{\mathrm{p}}$ :

$$
A_{p}=\frac{A_{\varepsilon p, c}}{A_{\varepsilon p, r e f}}
$$

$\mathrm{A}_{\varepsilon p, c}$ is the area surrounded by the equivalent plastic strain $\left(\varepsilon_{\mathrm{p}}\right)$ isolines ahead of the crack tip and $A_{\varepsilon p, r e f}$ is the reference area surrounded by the $\left(\varepsilon_{\mathrm{p}}\right)$ isolines in a standard test.

Yang et al. [38] found that a sole linear relation between the ratio of the current and the reference fracture toughness $J_{C} / J_{\text {ref }}$ exists. This is restricted to the case for dissimilar metal welded joints regardless of the in-plane and out-of-plane constraints for a crack. This relationship is independent on the selection of the $\varepsilon_{\mathrm{p}}$ isolines for higher $\varepsilon_{\mathrm{p}}$ values and can be regarded as a unified reference line to characterize the dependence of fracture resistance of a crack on the constraint.

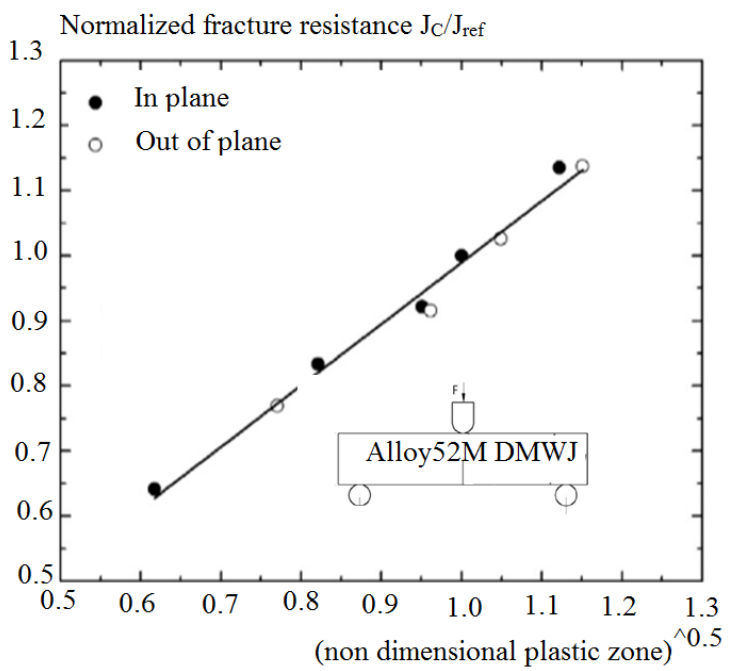

Fig. 9: Normalized fracture resistance $J_{C} / J_{\text {ref }}$ versus $\sqrt{ } A_{p}$ for cracked dissimilar metal welded joints, obtained from $\varepsilon_{\mathrm{p}}=1.0$ isolines [38]. 


\section{FACTORS OF INFLUENCE ON CONSTRAINT}

Values of the constraints $\mathrm{T}_{\mathrm{ef}}, \mathrm{Q}$, and stress triaxiality are sensitive to specimen geometry, loading mode, ligament size, and load level. Some examples of these effects are given as follows.

\section{Loading mode}

It has been noted that $\mathrm{T}$ stress can be negative or positive. In Table 1, the critical effective $\mathrm{T}$ stress for four specimens used for fracture test has been reported. These specimens have a notch of $0.25 \mathrm{~mm}$ radius and are made in X 52 pipe steel. Four types of specimens are examined: single edge notch tensile (SENT), CT, Roman tile (RT), and DCB.

Table 2: Values of $\mathrm{T}_{\mathrm{ef}, \mathrm{c}} / \sigma_{\mathrm{y}}$ for four specimen types (SENT, CT, RT, and DCB).

\begin{tabular}{|l|l|l|l|l|}
\hline Specimen & SENT & CT & RT & DCB \\
\hline $\mathrm{T}_{\mathrm{ef}, \mathrm{c}} / \sigma_{\mathrm{y}}$ & {$[-0.74 ;-0.80]$} & {$[-0.53 ;-0.67]$} & {$[-0.25 ;-0.30]$} & {$[+0.19 ;+0.21]$} \\
\hline
\end{tabular}

In general, specimens loaded in tension like CCT or SENT have a high negative effective T stress and are therefore less constrained. Specimens in bending like TPB or CT have lower negative $T$ stress and higher constraint [39]. DCB always has positive values. In the next section, we will discuss the consequence for crack bifurcation.

For the CT specimen, some contradictory results can be found in literature. The effective T stress is sometimes negative and sometimes positive. These differences can be explained by the definition of the effective T stress, the ligament size, the load level, and so on.

\section{Thickness}

The effect of thickness on constraint is explained later as the effect of out-of-plane constraint.

\section{Ligament size}

Figure 10 depicts the constraint parameter $\mathrm{T}_{\text {ef }}$ distribution for the $\mathrm{CT}$ specimen (width $\mathrm{W}=$ $63.80 \mathrm{~mm}$, height $=61 \mathrm{~mm}$, thickness $=5.84 \mathrm{~mm}$, notch radius $=0.25 \mathrm{~mm}$ ) in plane stress. The relative notch depth a/W varies in the range 0.1 to 0.7 and the applied load is constant for each value of a/W and equal to $1000 \mathrm{~N}$. The value of effective $\mathrm{T}$ stress $\mathrm{T}_{\mathrm{ef}}$ is associated with the effective distance, which varies with a/W [40].

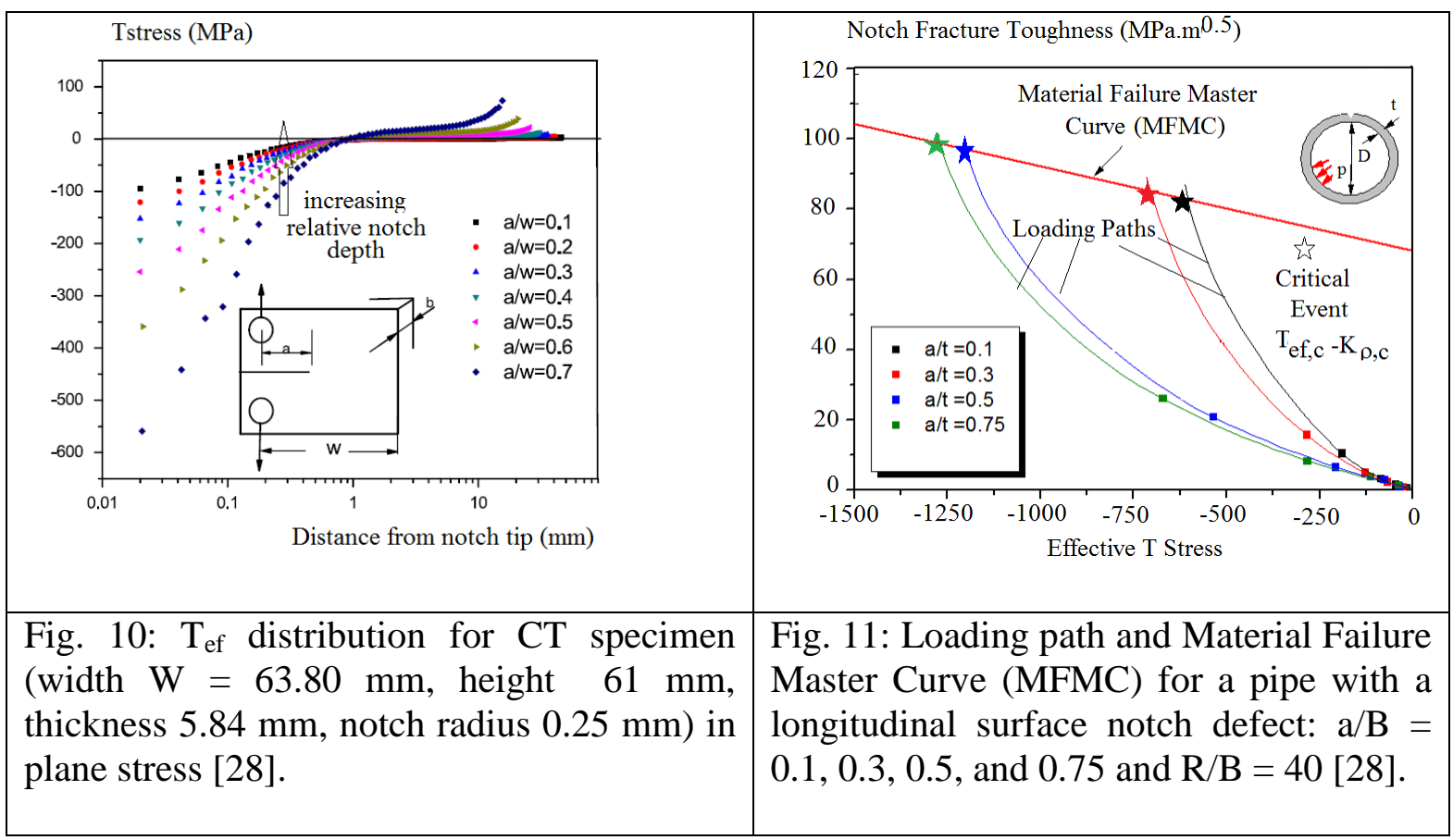


One notes that the value of $\mathrm{T}_{\text {ef }}$ increases when a/W increases. This result is confirmed by [41], where $T, Q, \beta$, and $A_{2}$ are computed for a clamped single-edge tension specimen. The relative crack depth varies in the range $\mathrm{a} / \mathrm{W}=0.3-0.7$ at the loading level of $\mathrm{J} /\left(\mathrm{b} \sigma_{0}\right)=0.01$, where $\mathrm{b}$ is the ligament size. These authors indicate that, in general, $\mathrm{T},-\mathrm{Q}, \beta$, and $-\mathrm{A}_{2}$ increase as $\mathrm{a} / \mathrm{W}$ increases; however, the impact of a/W is relatively small.

\section{Loading path in plane $K_{a p}-T_{f}$}

A negative value of the $T_{\text {ef }}$-parameter increases with the applied load generally according to a parabolic function for low values of the applied load or pressure and becomes practically linear when the load value increases. In the plane applied stress intensity factor-effective $\mathrm{T}$ stress, all the assessment points follow a non-linear curve, which is the so-called loading path. The loading path intercepts the MFMC at the point $\mathrm{K}_{\rho, \mathrm{c}}-\mathrm{T}_{\text {ef,c }}$-parameter (or $\mathrm{K}_{\mathrm{c}}$ if the defect is a crack) at the critical event. Figure 11 gives an example of different loading paths for a pipe made of X52 steel. The pipe exhibits a longitudinal surface notch defect with relative depth $\mathrm{a} / \mathrm{B}: \mathrm{a} / \mathrm{B}=0.1,0.3,0.5$, and 0.75 , and relative radius $\mathrm{R} / \mathrm{B}=40$, where $\mathrm{B}$ is the wall thickness of the pipe.

\section{INFLUENCE OF CONSTRAINT ON FRACTURE TOUGHNESS}

Eisele et al. [42] pointed out that the fracture toughness $K_{c}$ or $J_{c}$ increases with the loss of constraint $\mathrm{T}$ stress, $\mathrm{A} 2$ or $\mathrm{Q}$.

This can been seen in Fig. 12, where the $\mathrm{J}_{\mathrm{C}} \mathrm{Q}$ locus of a low carbon manganese cast steel is plotted [43]. Three-point bending tests were used for fracture behaviour determination. Fracture toughness was determined using three test specimen geometries. The first one was the standard three point bend specimen $25 \times 50 \times 220 \mathrm{~mm}$ with a ratio a/W $=0.5$. The other ones were selected to receive shallow cracks (specimen 1: a/W $=0.1 ; 25 \times 30 \times 130 \mathrm{~mm}$; specimen 2 : $\mathrm{a} / \mathrm{W}=0.2 ; 25 \times 27 \times 120 \mathrm{~mm}$ ). The stress distribution using the standard method for Q-parameter determination was computed by the finite element method at load level corresponding to the fracture force.

One notes that the fracture toughness decreases when the constraint increases; that is, the Qparameter increases.

Hadj Meliani et al. [44] have also pointed out this effect on the notch fracture toughness $\mathrm{K}_{\rho}, \mathrm{c}$ with the critical constraint described by the $\mathrm{T}_{\mathrm{ef}}$-parameter. The material used in this study is API X52 steel .

Several specimens of four types, namely CT, DCB, SENT, and RT, were extracted from a steel pipe of diameter $610 \mathrm{~mm}$. The geometries of these specimens were as follows: SENT specimen: thickness $=5.8 \mathrm{~mm}$, width $=58.40 \mathrm{~mm}$; CT specimen: thickness $=5.8 \mathrm{~mm}$, width $=63.80 \mathrm{~mm}$, height $=61 \mathrm{~mm} ;$ DCB specimen: thickness $=5.8 \mathrm{~mm}$, height $=45.70 \mathrm{~mm}$; RT specimen: thickness $=5.8 \mathrm{~mm}$, width $=40 \mathrm{~mm}$, length $=280 \mathrm{~mm}$. The specimens have a notch with a notch angle $\psi=0$ and a notch radius $\rho=0.25 \mathrm{~mm}$ and an a/W ratio in the range 0.3-0.6. The stress distribution used was computed by the finite element method at a load level corresponding to the fracture force. $\mathrm{T}_{\mathrm{ef}}, \mathrm{c}$ was determined by the volumetric method. It can be noted in Fig. 13 that the fracture toughness decreases linearly with the constraint according to

$K_{\rho, c}=a T_{e f, c}+K_{\rho, c}^{0}$ 
where $K_{\rho, c}^{0}$ is the fracture toughness corresponding to $T_{e f, c}=0$, which is considered as a reference. $a=-0.069$ and $K_{\rho, c}^{0}=77.2 \mathrm{MPa} \sqrt{m}$ for the API X52 pipe steel.

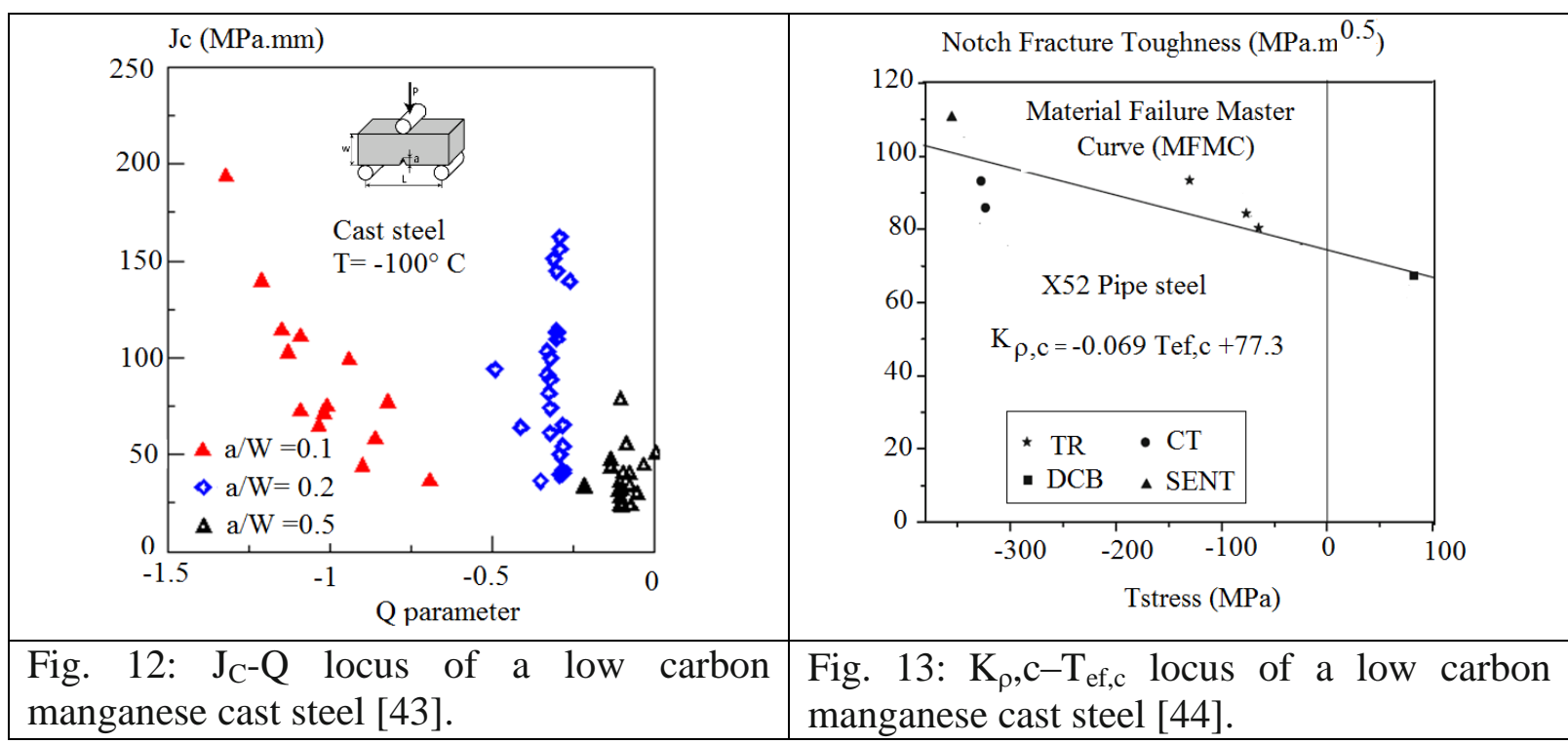

\section{INFLUENCE OF CONSTRAINT ON TRANSITION TEMPERATURE}

Wallin [45] has established a new MFMC, where the fracture toughness $K_{c}$ is a function of the temperature $\mathrm{T}$ and the $\mathrm{T}$ stress. The standard master curve $\mathrm{K}_{0}$ corresponding to a reference temperature $\mathrm{T}_{0}$ has the form

$\mathrm{K}_{0}=31+77 \cdot \exp \left(0.019\left[\mathrm{~T}-\mathrm{T}_{0}\right]\right)$

1. $\mathrm{T}_{0}$ is the transition temperature corresponding to a conventional value of fracture toughness of $100 \mathrm{MPa} \sqrt{\mathrm{m}}$. All materials have a similar exponential evolution of fracture toughness with temperature $\mathrm{T}$ are characterized by a single parameter $\mathrm{T}_{0}$.

In order to account for the constraint effect in the MFMC, Wallin [45] assumed that the reference temperature is constraint dependent. A linear relation was found between the reference temperature $\mathrm{T}_{0}$ and the $T_{\text {stress }}$.

$$
\begin{gathered}
T_{0}(T)=T_{0, \text { ref }} \text { for } T_{\text {stress }}>0 \\
T_{0}\left(T_{\text {stress }}\right)=T_{0, \text { ref }}+\frac{T_{\text {stress }}{ }^{\circ} \mathrm{C}}{10} \text { for } T_{\text {stress }}<0
\end{gathered}
$$

$T_{0, r e f}$ is the reference temperature for a reference constraint as obtained for small scale yielding or for $\mathrm{T}_{\text {stress }}=0$.

More generally, Wallin [46] proposed:

$$
T_{0}=T_{0 . T=0}+\frac{A T_{\text {stress }}}{\sigma_{y}}
$$

A is a new parameter. To assess the validity of Eq. (31), Hohe et al. [47] presented the results of fracture resistance of nuclear grade $22 \mathrm{NiMoCr} 3-7$ pressure vessel steel as a linear 
regression analysis of both the fracture toughness $\mathrm{K}_{\mathrm{Jc}}$ and the respective secondary fracture parameter $\mathrm{Y}\left(\mathrm{T}_{\text {stress }} / \sigma_{0}, \mathrm{Q}, \mathrm{A}_{2}\right.$, or $\beta$ respectively).

$$
\mathrm{T}_{0}=\mathrm{cY}+\mathrm{d}
$$

The parameters $\mathrm{c}$ and $\mathrm{d}$ are determined by means of a least squares minimization. The results are given in Table 3. Table 2 shows the linear regression parameters for the constraint dependence of the reference temperature, reference constraint value, and constraint indexing master curve reference temperature $T_{0}^{C I}[47]$.

Table 3. Parameters of linear regression analysis using Eq. (32) for fracture resistance of nuclear grade $22 \mathrm{NiMoCr} 3-7$ pressure vessel steel

\begin{tabular}{|l|l|l|l|l|}
\hline $\mathrm{Y}$ & $\mathrm{c}\left({ }^{\circ} \mathrm{C}\right)$ & $\mathrm{c}\left({ }^{\circ} \mathrm{C}\right)$ & $\mathrm{Y}_{\text {ref }}$ & $T_{0}^{C I}\left({ }^{\circ} \mathrm{C}\right)$ \\
\hline $\mathrm{T}_{\text {stress }} / \sigma_{0}$ & 51.4 & -68.6 & 0.40 & -56.9 \\
\hline $\mathrm{Q}$ & 47.2 & -59.8 & 0.20 & -53.9 \\
\hline $\mathrm{A}_{2}$ & 203.4 & -0.16 & -0.20 & $-55-8$ \\
\hline$\beta$ & 40.6 & -157.0 & 2.72 & -53.7 \\
\hline
\end{tabular}

A similar relation was found for X65 pipe steel by Coseru et al. [48] between various transition temperatures $T_{t}\left(T_{t}\right.$, tensile, $T_{0}$, and $\left.T_{K 1 / 2}\right)$ and the critical effective $T$ stress, $T_{\text {ef,c. }}$.

$T_{t}=T_{t . T e f, c=0}+0.14 T_{e f, c}$

This equation represents the Material Transition Temperature Master Curve (MTTMC) $T_{t}=f$ $\left(T_{\text {ef,c }}\right)$, which is the key to determining the appropriate reference transition temperature by comparison with the structure transition temperature.

In Fig. 14, the determination of the MTTMC of API X65 pipe steel was done using three specimen types (tensile, CT, and Charpy) [48]. Different Charpy specimens were used: Charpy V specimens (V notch, notch radius $\rho=0.25 \mathrm{~mm}$, notch depth $\mathrm{a}=2 \mathrm{~mm}$ ), Charpy $\mathrm{U}_{1}$ ( $U$ notch, notch radius $\rho=1 \mathrm{~mm}$, notch depth $\mathrm{a}=5 \mathrm{~mm}$ ), and Charpy $\mathrm{U}_{0.5}$ (U notch, notch radius $\rho=0.5 \mathrm{~mm}$, notch depth $\mathrm{a}=5 \mathrm{~mm}$ ), and the transition temperatures of the Charpy specimens were corrected to take into account the influence of the loading rate.

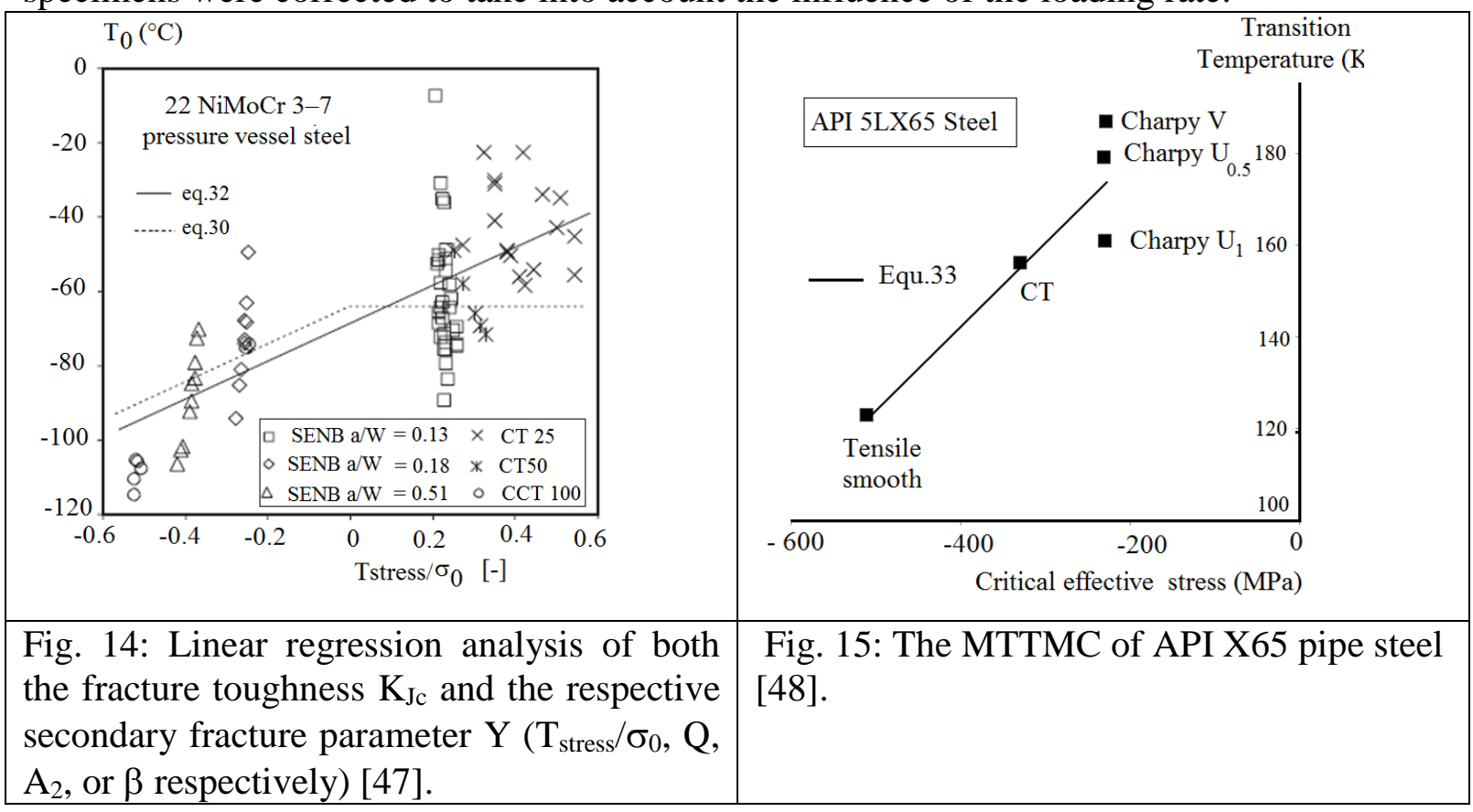


The MFMC was modified by Wallin. By combining (29) with (31), he obtains:

$\mathrm{K}_{0}=31+77 \cdot \exp \left(0.019\left[\mathrm{~T}-\mathrm{T}_{0, \mathrm{~T} \text { stress }=0}-\frac{\mathrm{T}_{\text {stress }}}{12 \mathrm{MPa} /{ }^{\circ} \mathrm{C}}\right]\right)$

$\mathrm{K}_{0}$ represents the lower bound of the notch fracture toughness because it is determined with pre-cracked specimens. A similar MFMC was made for the notch fracture toughness [49] of notched specimens like the Charpy and obtained from the fracture energy $\mathrm{U}_{\mathrm{c}}$ :

$\mathrm{J}_{\rho, \mathrm{c}}=\frac{\eta \mathrm{U}_{\mathrm{c}}}{\mathrm{Bb}}$

where B is the thickness and $b$ the ligament size. Eta $(\eta)$ is a parameter for the proportionality between the specific fracture energy per ligament area and the notch fracture toughness. It depends on the notch radius and relative notch depth a/W. Akkouri et al. [50] tabulated the values of eta for different notch radii and relative notch depths. All data are fitted to the following equation:

$$
\mathrm{J}_{\rho, \mathrm{c}}=\mathrm{A}_{\mathrm{J}, \rho}+\mathrm{B}_{\mathrm{J}, \rho} \tanh \left[\frac{(\Delta \mathrm{T} *-)}{\mathrm{C}_{\mathrm{K}, \rho}}\right]
$$

with

$$
\Delta \mathrm{T} *=\mathrm{T}-\mathrm{T}_{\mathrm{t} . \mathrm{Tef}, \mathrm{c}=0}-0.14 \mathrm{~T}_{\mathrm{ef}, \mathrm{c}}
$$

$\Delta \mathrm{T}^{*}$ represents the shift of the test temperature with the transition temperature in function of constraint $T_{\text {ef,c. }} . T_{t . T e f, c=0}$ is the transition temperature corresponding to a constraint equal to zero and used as reference (197 K for API X65 pipe steel).

The definition of a general constraint-dependent master curve reference temperature $T_{0}(Y)$ results in the introduction of a material parameter $\mathrm{T}_{0}$, which additionally depends on the actual loading situation. This implies a proper separation of material and loading parameters, This problem was avoided by [47] by the use of a master curve defined as an exponential function. One of the basic features of this type of function is that a shift in the direction of the argument coincides with a scaling of the function itself. A constraint-dependent scaling of the stress intensity factors according to:

$$
\left.K_{J}^{\mathrm{ref}}(T, Y)=30 \mathrm{MPa} \mathrm{m}^{1 / 2}+\left(K_{J}(T)-30 \mathrm{MPa} \mathrm{m}^{1 / 2}\right) \mathrm{e}^{0.019_{c}\left(Y-Y^{\mathrm{ref}}\right)}\right)
$$

where $Y_{\text {ref }}$ denotes the constraint parameter for a reference case. Through this procedure, a constraint indexing master curve reference temperature $T_{0}^{C I}$ is established, defining a material curve that is independent of the actual loading situation. Values of $Y_{\text {ref }}$ and $T_{0}^{C I}$ for nuclear grade 22 NiMoCr 3-7 pressure vessel steel are given in Table 3.

\section{T STRESS AND CRACK PATH}

Cotterel [51] has pointed out the role of $\mathrm{T}$ stress in crack curving. The $\mathrm{T}$ stress is a stress which acts parallel to the crack direction. Therefore, this stress combined with the opening stress induces a mixed mode of loading with a biaxiality ratio $\Theta$ : 


$$
\Theta=\frac{T \sqrt{\pi \cdot a}}{K_{I}}
$$

The maximum stress along the $\sigma_{\theta \theta}$ distribution is not always null for $\theta=0$ and angular deviation can occur only for positive values of $\mathrm{T}$ stress. When the $\mathrm{T}$ stress is negative, the maximum $\sigma_{\theta \theta}$ is always along the direction of propagation $\theta=0$.

If $\mathrm{T}$ stress is positive, the crack curves according to the criterion of maximum tangential stress introduced by Erdogan and Sih [50]. By applying this criterion, the opening stress is given by

$$
\begin{gathered}
\sigma_{\theta \theta}=\frac{K_{I}}{\sqrt{2 \pi r}}\left[\frac{3}{4} \cos \frac{\theta}{2}+\frac{1}{4} \cos \frac{3 \theta}{2}\right]+T \sin ^{2}(\theta) \\
\frac{\sqrt{2 \pi r} \cdot \sigma_{\theta \theta}}{K_{I}}=\left[\frac{3}{4} \cos \frac{\theta}{2}+\frac{1}{4} \cos \frac{3 \theta}{2}\right]+\frac{T \sqrt{2 \pi r}}{K_{I}} \sin ^{2}(\theta)
\end{gathered}
$$

The evolution of the ratio $\frac{\sqrt{2 \pi r} \cdot \sigma_{\theta \theta}}{K_{I}}$ with the direction of propagation $\theta$ is plotted in Fig. 16 for positive or negative values of $\mathrm{T}$. The maximum opening stress is indicated by a black spot for positive $\mathrm{T}$ stress. For negative $\mathrm{T}$ stress, this maximum occurs for negative values of opening stress and bifurcation cannot occur because the crack surfaces cannot overlap.

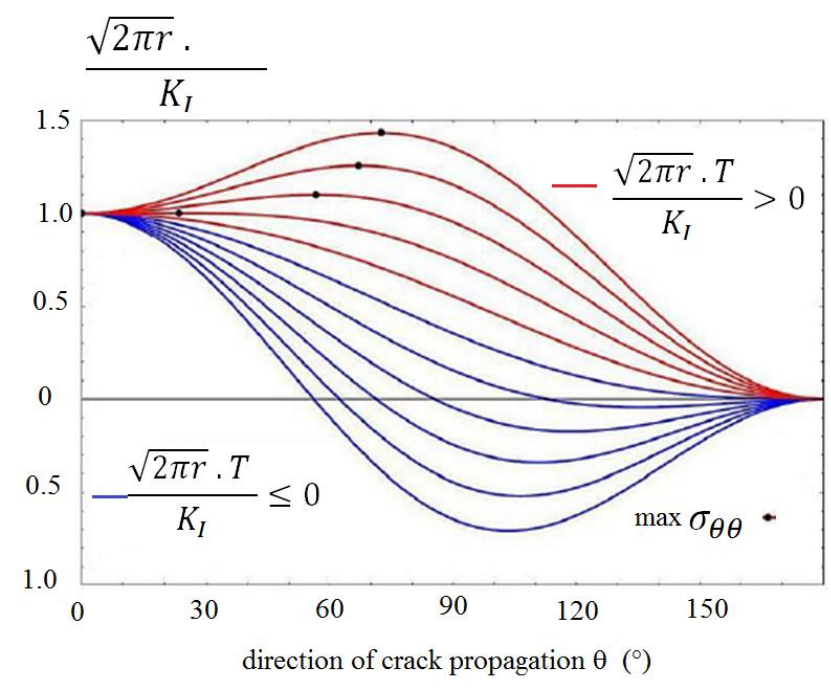

Fig. 16. Evolution of the ratio $\frac{\sqrt{2 \pi r} \cdot \sigma_{\theta \theta}}{K_{I}}$ with crack propagation direction $\theta$ in the presence of T stress.

The bifurcation direction $\theta^{*}$ is given when the first derivative of Eq. (42 is equal to zero.

$$
\theta^{*}=\cos ^{-1}\left[\frac{1+\sqrt{1+\frac{1024 \pi}{9} \cdot X_{e f} \cdot\left(\frac{T_{C}}{K_{I c}}\right)^{2}}}{\frac{512 \pi}{9} \cdot X_{e f} \cdot\left(\frac{T_{c}}{K_{I c}}\right)^{2}}\right]
$$


and the second derivative must be negative. Chao et al. [51] introduced the RKR criterion in this analysis. At fracture $K_{I}=K_{c}, T=T_{c}$ and $\sigma_{\theta \theta}=\sigma_{c}$ for $x=X_{e f}$, . The bifurcation direction is $\theta^{*}$ and $\mathrm{X}_{\mathrm{ef}}$ is the size of the fracture process volume or effective distance. The condition on the second derivative implies that for crack curving

$\frac{T_{c}}{K_{c}}>\frac{3}{8} \frac{1}{\sqrt{2 \pi X_{e f}}}$

Figures 17 and 18 gives an example of a DCB specimen with positive $\mathrm{T}$ stress and crack curving. The CT specimen also has a positive T stress and non-curving crack.

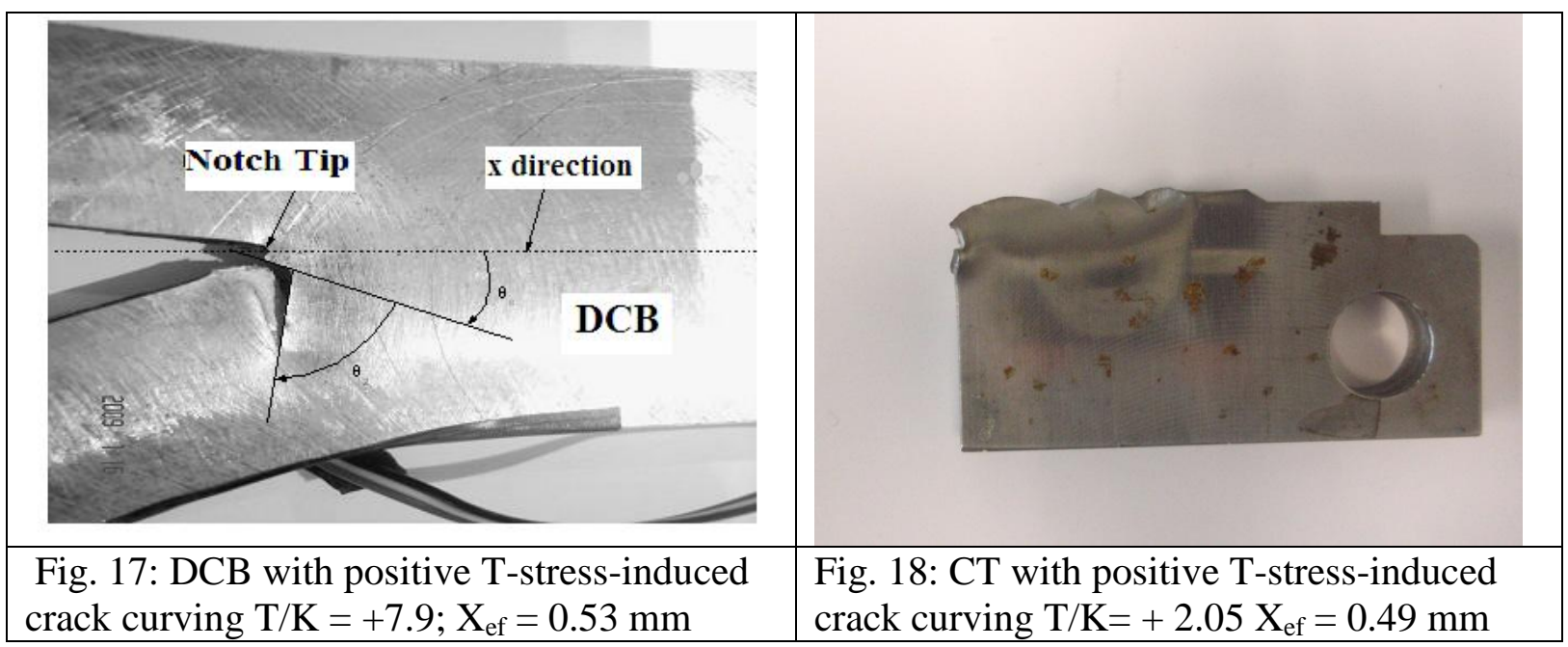

For negative $\mathrm{T}$ stress, after initiation, the crack propagates firstly in an instable manner and secondly after several millimetres in a stable manner. During crack propagation in a stable manner,crack tip opening angle CTOA remains constant and its constant value is a characteristic of the fracture resistance of the material. It can be noted that during the stable crack propagation both CTOA and $\mathrm{T}$ stress are constant.

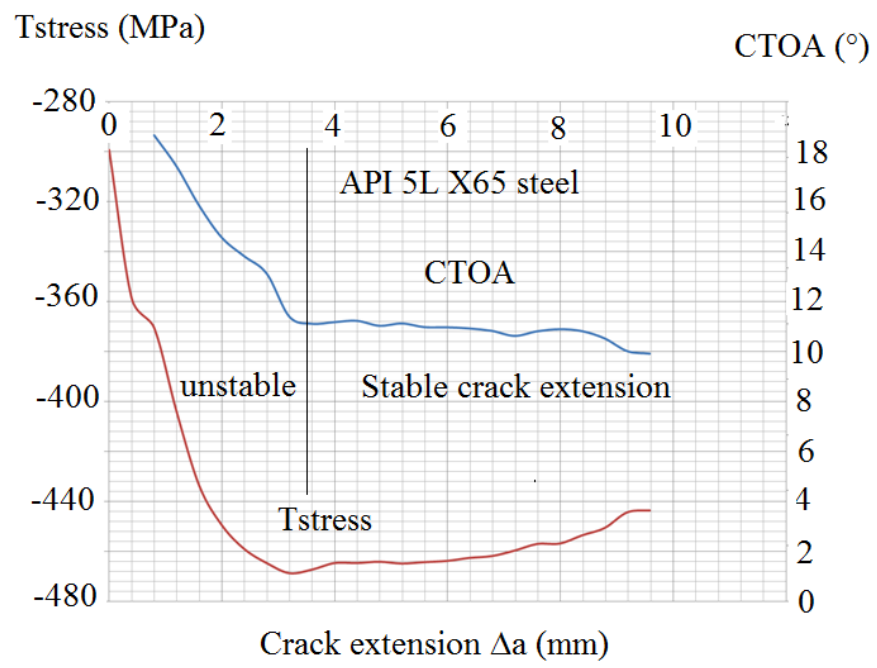

Fig. 19: Evolution of CTOA and T stress during crack propagation. Steel API 5L X65. 


\section{EFFECT OF THICKNESS ON FRACTURE TOUGHESS AND OUT-OF-PLANE CONSTRAINT}

It is well known now that fracture toughness $\left(\mathrm{K}_{\mathrm{c}}\right.$ or $\left.\mathrm{J}_{\mathrm{c}}\right)$ decreases when the thickness increases. The fracture toughness is maximal for plane stress conditions and trends asymptotically to a minimum called $\mathrm{K}_{\mathrm{Ic}}$ or $\mathrm{J}_{\mathrm{Ic}}$ if the plane strain conditions are satisfied. Therefore a description of fracture resistance cannot be done with a single parameter. Zhao and Guo [54] proposed to described the effect of thickness $B$ on fracture toughness $K_{c}=f(B)$ by introducing "a triaxial stress constraint" $\mathrm{T}_{\mathrm{z}}$. This parameter is defined as:

$$
T_{Z}=\frac{\sigma_{z z}}{\sigma_{y y}+\sigma_{x x}}
$$

For a straight crack through the thickness, which is a typical case of $3 \mathrm{D}$ cracks, $\mathrm{y}$ is the direction normal to the crack plane xoz. In an isotropic linear elastic cracked body, $\mathrm{T}_{\mathrm{z}}$ ranges from 0 to $\mathrm{N}, \mathrm{T}_{\mathrm{Z}}=0$ for the plane stress state, and $\mathrm{T}_{\mathrm{z}}=\mathrm{N}$ for the plane strain state, where $\mathrm{N}$ is the strain hardening exponent of the Ramberg-Osgood strain-stress relationship.

In order to take into account the thickness effect it is necessary to have a 3D descriptions of the singularity and angular distribution of stresses and strains as a function of the triaxial stress constraint $\mathrm{T}_{\mathrm{z}}$ :

$$
\begin{gathered}
\sigma_{i j}=\left[\frac{J}{\alpha \varepsilon_{0} \varepsilon \sigma_{0} I\left(T_{z}, N\right) r}\right]^{1 / N+1} \widetilde{\sigma_{l j}}\left(\theta, T_{z}\right) \\
\varepsilon_{i j}=\frac{3}{2} \alpha\left[\frac{J}{\alpha \varepsilon_{0} \varepsilon \sigma_{0} I\left(T_{z}, N\right) r}\right]^{N / N+1} \widetilde{\varepsilon_{l j}}\left(\theta, T_{Z}\right)
\end{gathered}
$$

These forms are similar to that of an HRR solution, but $\mathrm{J}$ may be path dependent and $\mathrm{I}$ is a function of $T_{z}$ and N. $\alpha$ is the coefficient of the Ramberg-Osgood law, $\sigma_{0}$ the reference stress, and $\varepsilon_{0}$ the strain associated to the reference stress. $\widetilde{\sigma_{l j}}$ and $\widetilde{\varepsilon_{l j}}$ are eigenvalues. I is a complex function of eigenvalues of stresses and displacements.

With this kind of stress distribution the $T$ stress depends on relative thickness $z_{B}=z / B$ and is expressed as

$$
T=\sigma_{g} \bar{T}\left(v, z_{B}\right)
$$

where the function $\bar{T}$ presents a non-dimensional function and can be given as :

$\bar{T}\left(\nu, z_{B}\right)=B_{0}+\frac{B_{1} \exp \left(z_{B}-B_{2}\right)}{B_{3}}$

$\mathrm{B}_{0}, \mathrm{~B}_{1}, \mathrm{~B}_{2}$, and $\mathrm{B}_{3}$ are coefficients in function of the Poisson ratio $\mathrm{v}$.

For a pure mode I cracked plate, Zhao and Guo [54] developed a 3D fracture criterion considering the out-of-plane stress constraint $\mathrm{T}_{\mathrm{z}}$. The thickness-dependent fracture toughness 
is predicted using the equivalent thickness concept. This means that the in-plane distribution of $T_{z}$ at the point $P$ is the same as that at the mid-plane of a plate with a thickness of $B_{e q}$ :

$$
B_{e q}=\left(1-z_{B}^{2}\right)
$$

The three-dimensional fracture toughness in the pure mode $\mathrm{I}, \mathrm{K}_{\mathrm{I} z, \mathrm{c}}$, is a function of the fracture toughness associated with different thicknesses as:

$$
\begin{aligned}
K_{I Z, C}=K_{c}(B) \sqrt{f\left(\overline{T_{Z I}\left(B_{e q}\right)}\right)} & \\
f\left(\overline{T_{Z I}\left(B_{e q}\right)}\right) & =\frac{2}{3}(1+v)+\frac{4}{3}(1-2 v)\left(\frac{1+\overline{T_{Z I}}}{1-2 \overline{T_{Z I}}}\right)^{2} \\
T_{Z I} & =\frac{1}{\overline{r_{p}} B_{e q}} \int_{0}^{\overline{r_{p}}} \int_{0}^{B_{e q}} \bar{T}_{Z I} d z d r
\end{aligned}
$$

where $\overline{r_{p}}$ is the mean radius of the crack-tip plastic zone along the thickness.

Zhao and Guo [54] have tested this model on LY12-CZ aluminium alloy standard CT specimens. Figure 20 indicates that the fracture toughness of this alloy is strongly dependent on the thickness. After considering the equivalent thickness $B_{\text {eq }}$ from Eq. (49), we can find that the three-dimensional fracture toughness in pure mode $\mathrm{I}, \mathrm{K}_{\mathrm{Iz}, \mathrm{c}}$, is almost a constant and is independent of the thickness.

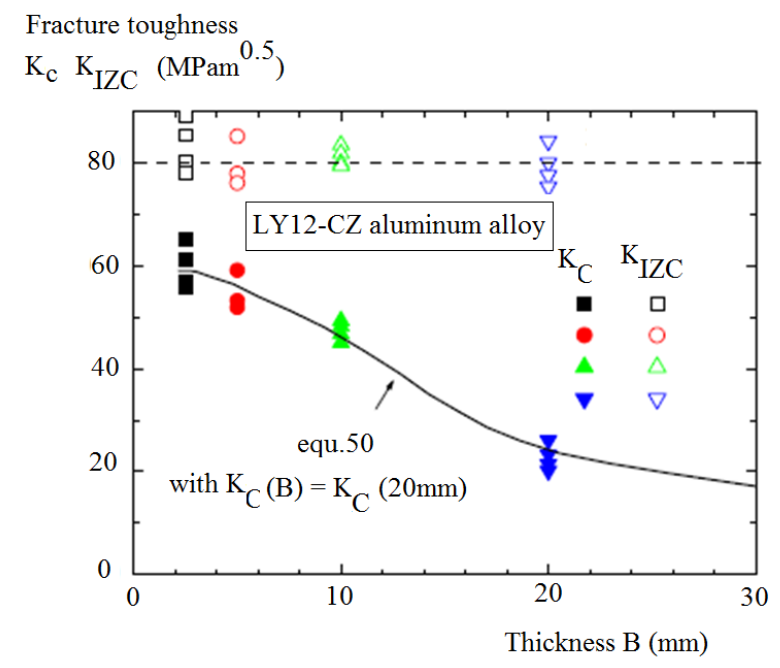

Fig. 20: Determination of the three-dimensional fracture toughness in pure mode $\mathrm{I}, \mathrm{K}_{\mathrm{Iz}, \mathrm{c}}$, on LY12-CZ aluminium alloy [54]. 


\section{INFLUENCE OF STRESS GRADIENT ON MECHANICAL PROPERTIES}

Aifantis [55] has proposed a modification of plastic flow rule including a plastic strain Laplacian.

$$
f=\sigma V M-\left(\Phi(\varepsilon p l, e q)-c \nabla^{2} \varepsilon p l, e q\right)=0
$$

$\sigma_{V M}$ is the von Mises equivalent stress and epl,eq $_{\text {the }}$ plastic equivalent strain.

$$
\bar{\varepsilon} p l, e q=\frac{1}{l_{c}} \cdot \int_{-\infty}^{\infty} \alpha(u)_{\varepsilon} p l, e q \cdot(x+u) d u \text { with } \mathrm{u}=\mathrm{s}-\mathrm{X}
$$

If we assume that $\varepsilon_{\mathrm{pl}, \mathrm{eq}}$ varies slowly, we can approximate $\varepsilon_{p l, e q} \cdot(x+u)$ by a Taylor development:

$$
\bar{\varepsilon}_{p l, e q}=\varepsilon_{p l, e q}(x)+\frac{\partial \varepsilon p l, e q}{\partial x}(x) l_{c} \mu_{1}+\frac{\partial^{2} \varepsilon p l, e q}{\partial^{2} x}(x) l_{c}^{2} \mu_{2}+\ldots+\frac{\partial^{n} \varepsilon p l, e q}{\partial^{n} x}(x) l_{c}^{n} \mu_{n}
$$

with $\mu_{i}=\int_{-\infty}^{\infty} \alpha(s) \frac{s^{n} d s}{l_{c}^{n+1}}$

where $\alpha(s)$ is a pair function. $\mu_{\mathrm{i}}$ values are zero for odd values of i. By limiting Taylor development to two terms:

$$
\bar{\varepsilon} p l, e q \approx \varepsilon p l, e q(x)+\frac{\partial \varepsilon p l, e q}{\partial x}(x) l_{c} \mu_{1}+\frac{\partial^{2} \varepsilon p l, e q}{\partial^{2} x}(x) l_{c}^{2} \mu_{2}
$$

The non-intrinsic character of mechanical properties is also explained by the stress gradient. Malmberg [56] has used a local approach based on strain gradient to explain the evolution of yield shearing stress in torsion.

$$
\tau=G \gamma=G \varphi r
$$

where $G$ is the shearing modulus, $\gamma$ the shearing strain, $r$ the specimen radius, and $\phi$ the rotation angle.

In the plastic region, the plastic flow rule includes gradient terms

$$
\tau=\tau_{y}-c_{1} \nabla \gamma-c_{2} \nabla^{2} \gamma=\tau_{y}-c_{1} \varphi-c_{2} \frac{\varphi}{r}
$$

where $\tau_{\mathrm{y}}$ is the shearing yield stress and $\mathrm{c}_{1}$ and $\mathrm{c}_{2}$ are constants. 
Apparent yield stress/ yield stress

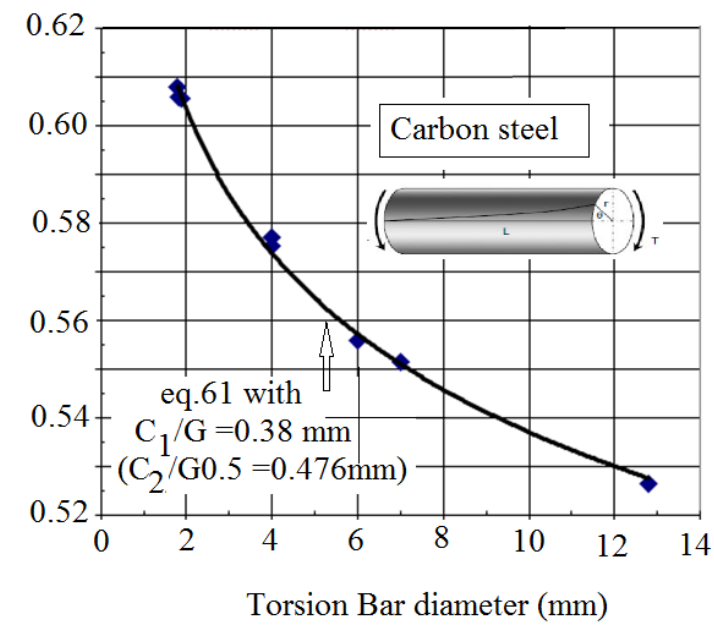

Fig. 21. Applications of Malmberg [22] to bars in torsion.

At the boundary between elastic and plastic region we have:

$$
\begin{aligned}
& \mathrm{r}=\mathrm{r}_{\mathrm{y}} ; \tau=\tau_{\mathrm{y}} \\
& \tau_{y, a p}=G \varphi_{r_{y}}=\tau_{y}-c_{1} \varphi-c_{2} \frac{\varphi}{r_{y}}
\end{aligned}
$$

$\tau_{\mathrm{y} \text {,ap }}$ is the apparent yield stress in torsion and $r_{\mathrm{y}}$ is the radius of the elastic boundary. The apparent yield stress is obtained when $r_{y}=r *$, where $r^{*}$ is the specimen radius.

The scaling law on shearing yield stress can be written as:

$$
\tau_{y, a p}=\frac{\tau_{y}}{\left(1+\frac{\left(c_{1} / G\right)+\left(c_{2} / G\right) \cdot r^{*}}{r^{2}}\right)}
$$

Figure 21 shows applications of Malmberg's model [22].

\section{INFLUENCE OF RELATIVE STRESS GRADIENT ON FATIGUE}

The influence of the stress gradient is mainly evidenced on fatigue resistance. Figure 22 shows Wohler curves obtained on smooth specimens made of carbon steel (yield stress $\mathrm{Re}=$ $312 \mathrm{MPa}$ and ultimate stress $\mathrm{Rm}=500 \mathrm{MPa}$ ). SN curves (stress amplitude versus fatigue life duration) for smooth specimens subject to alternate torsion, alternate tension, and compression and rotating bending loading are presented in Fig. 22. In this figure, the results of compression and tension and rotating bending are presented as the magnitude of normal stress versus the number of cycles to failure. The torsion data are presented in two ways: shear amplitude versus number of cycles at failure and the amplitude of the equivalent von Mises stress versus the number of cycles to failure. This figure indicates that the mode of loading has a strong influence on the fatigue life of smooth specimens for the same stress amplitude. 


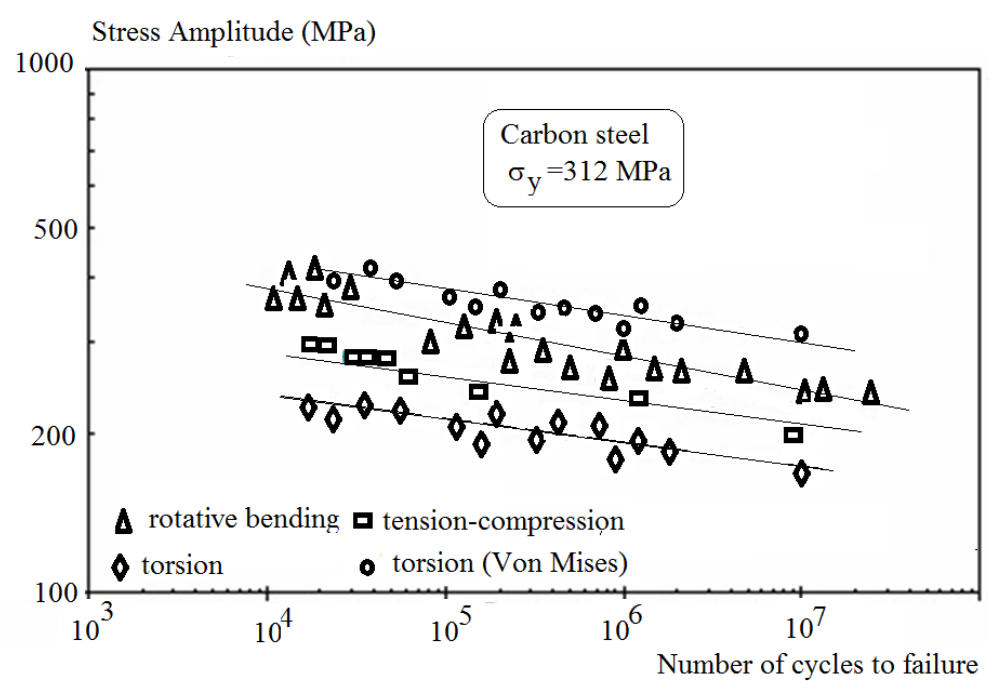

Fig. 22: SN curves for smooth specimens subject to alternate torsion, alternate tension, and compression and rotating bending loading.

Analysis of the results makes it possible to determine the parameters of Basquin's law, which has the general form:

$\Delta \sigma=\sigma_{\mathrm{f}, \mathrm{m}} \cdot \mathrm{N}_{\mathrm{R}}{ }^{\mathrm{b}, \mathrm{m}}$

where $\Delta \sigma, \sigma_{\mathrm{f}, \mathrm{m}}$, and $\mathrm{b}_{\mathrm{m}}$ are respectively the applied stress range, the Basquin's coefficient, and Basquin's exponent of fatigue curves for the three charging modes mentioned above $(\mathrm{m}=$ $\mathrm{T}, \mathrm{t}, \mathrm{b}$ for respectively traction, bending, or torsion).

Table 4. Basquin's coefficient and Basquin's exponent of fatigue curves for the three charging modes

\begin{tabular}{|l|c|c|}
\hline & $\sigma^{\prime}{ }_{\mathrm{f}}(\mathrm{MPa})$ & $\mathrm{b}$ \\
\hline Tension-compression & 470 & -0.05 \\
\hline Rotative bending & 887 & -0.08 \\
\hline Torsion & 337 & -0.04 \\
\hline
\end{tabular}

According to Brand et al. [57], the loading mode effect is properly taken into account by using the relative maximum stress gradient $\check{\chi}$ :

$$
\check{\chi}=\lim _{x \rightarrow 0} \frac{1}{\sigma_{\max }} \cdot \frac{d \sigma}{d x}
$$

where $\sigma_{\max }$ is the actual maximum stress at the notch root. The relative maximum stress gradient $\check{\chi}$ is expressed in millimetres ${ }^{-1}$.

Two notched specimens have the same net section at the bottom notch and are subject to the same bending moment. One has a low notch stress concentration factor $\mathrm{k}_{\mathrm{t}}$, and the other a high notch $\mathrm{k}_{\mathrm{t}}$ (Fig. 8.6). It is found that the slopes of the tangent to the stress field in the notch 
depth are different. After analysing a large number of fatigue data obtained on smooth and notched specimens, Brand proposed the following equation to determine the endurance limit:

$$
\hat{\sigma}_{D}=k_{t} \cdot \sigma_{D}=a \cdot \log \hat{\chi}+b
$$

where $\hat{\sigma}_{D}$ is the actual endurance limit for a probability of $90 \%$, and a and b are constants of the material data.

To predict a Wöhler curve in the presence of a notch, Brand proposed the following equation:

$$
\hat{\sigma}_{D N}=c_{2}+b_{2} \cdot \log N+a_{2} \cdot \log \hat{\chi}
$$

where $\hat{\sigma}_{D N}$ is the real fatigue limit corresponding to the number $\mathrm{N}$ of endurance cycles. $\mathrm{a}_{2}, \mathrm{~b}_{2}$, and $c_{2}$ are functions of the ultimate strength $\mathrm{Rm}$.

\section{INFLUENCE OF RELATIVE STRESS GRADIENT AN LOCAL FRACTURE STRESS}

The stress distribution at the notch tip described in Fig. 3 is modelled by a polynomial stress distribution written as:

$$
\sigma_{y y}(x)=\sum_{i=0}^{n} a_{i} x^{i}
$$

where $\sigma_{y y}(x), a_{i}$, and $x$ are the crack opening stress, polynomial coefficients, and distance along the notch direction, respectively. The relative stress gradient $\chi$ can be derived from (66) as:

$$
\chi(x)=\frac{1}{\sigma_{y y}(x)} \frac{\partial \sigma_{y y}(x)}{\partial x}=\frac{\sum_{i=0}^{n} i a_{i} x^{i-1}}{\sum_{i=0}^{n} a_{i} x^{i}}
$$

The effective distance $X_{\text {ef }}$ which corresponds to the point of minimum relative stress gradient can be obtained as below:

$$
\left.\frac{\partial \chi(x)}{\partial x}\right|_{x=X_{e f}}=-\frac{1}{\sigma_{y y}^{2}(x)}\left(\frac{\partial \sigma_{y y}(x)}{\partial x}\right)^{2}+\frac{1}{\sigma_{y y}(x)} \frac{\partial^{2} \sigma_{y y}(x)}{\partial x^{2}}=0
$$

Equation (68) can be substituted by Equation (69) and the resultant relation gives the "volumetric method effective distance characteristics equation" as: 


$$
\left(\sum_{i=0}^{n} a_{i} i X_{e f}^{i-1}\right)^{2}=\left(\sum_{i=0}^{n} a_{i} i .(i-1) X_{e f}^{i-2}\right) \times\left(\sum_{i=0}^{n} a_{i} X_{e f}^{i}\right)
$$

The effective stress $\sigma_{\text {ef }}$ which is the average value of the stress distribution in the fracture process zone is given by:

$$
\sigma_{e f}=\frac{1}{X_{e f}} \int_{0}^{X_{e f}}\left(\sum_{i=0}^{n} a_{i} x^{i}\right) \times \phi(x, \chi) d x
$$

In Eq. (69), the weight function $\phi$ is presented. The weight function deals with the stress contribution in the fracture process zone. The weight function explicitly depends on stress, stress gradient, and distance from notch root and implicitly depends on the notch geometry, loading type, boundary conditions, and material properties. The main objective of the weight function is to emphasize integrant quantity in a special range for predicting the equivalent or so-called effective stress.

The weight function can be chosen as unity. It leads to an equal stress or strain contribution for each point in the elaborated plastic zone and it can be denoted as the general form:

$$
\phi(x, y, z, \chi)=1
$$

where $x, y, z$, and $\chi$ are coordinates and the relative stress gradient, respectively. The mentioned weight function can be classified as the simplest weight function. Accordingly, the methods which signify the unit weight function must be deemed as Average or Line Method (LM), and the effective stress is given as:

$$
\sigma_{e f}=\frac{1}{X_{e f}} \sum_{i=0}^{n} \frac{a_{i} X_{e f f}^{i+1}}{i+1}
$$

The weight function is also proposed at a specified point around the notch root Erreur ! Source du renvoi introuvable.and it can be generally written as:

$$
\phi(x, y, z, \chi)=\delta\left(x-x_{0}\right) \delta\left(y-y_{0}\right) \delta\left(z-\mathrm{z}_{0}\right)
$$

where $x_{0}, y_{0}, z_{0}, \delta\left(x-x_{0}\right), \delta\left(y-y_{0}\right)$, and $\delta\left(z-\mathrm{z}_{0}\right)$ are coordinates of the specified point and delta functions, respectively. The delta function in the weight function definition describes the point method (PM). Indeed, the mathematical integration is omitted and the integrant value at a specific point is calculated due to the delta function feature. Consequently, the relation (72) reduces to:

$$
\sigma_{e f}=\sigma_{y y}\left(x_{0}, y_{0}, z_{0}\right)
$$

The presented weight functions in Eqs. (71) and (73) exclude the influence of the stress gradient. Yao et al. Erreur! Source du renvoi introuvable. suggested a weight function including the stress gradient at the notch root in polar form:

$$
\phi(r, \theta, \chi)=1-c_{s} \times|\chi| \times r \times f(\theta)
$$


where $c_{s}$ and $f(\theta)$ are the weight function skew factor and polar function for area integration purposes, respectively.

For LM integration, the polar function $f(\theta)$ is withdrawn and the skew factor is equal to 1 . Consequently, Eq. (75) is simplified as:

$$
\phi(x, \chi)=1-|\chi| \times x
$$

For the LM, including the weight function given by Eq. (76), the effective distance depends on the relative stress gradient $\chi$ :

$$
\sigma_{e f}=\left[\frac{1}{X_{e f}} \sum_{i=0}^{n} \frac{a_{i} X_{e f}^{i+1}}{i+1}-\frac{1}{X_{e f f}}|\chi| \times \sum_{i=0}^{n} \frac{a_{i} X_{e f f}^{i+2}}{i+2}\right]
$$

Equation (77) indicates that the effective stress based on the LM with the unit weight function is diminished by a second part including the existence of the stress gradient.

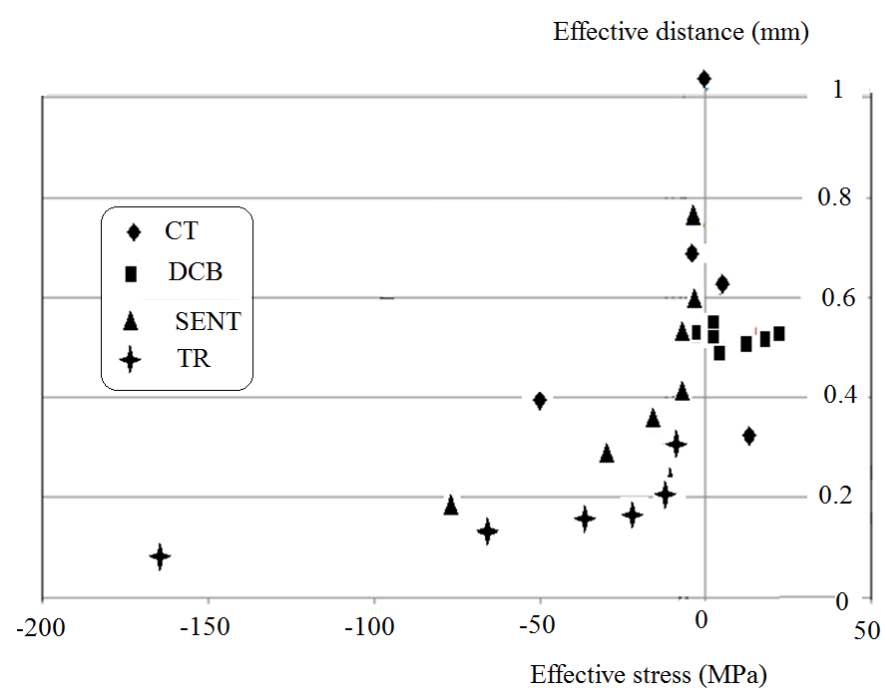

Fig. 23: Evolution of the effective distance versus effective $\mathrm{T}$ stress for an X52 steel pipe. Values obtained from four specimen types (CT, SENT, DCB, and RT).

The effective distance has been determined for four kinds of specimens used to determine fracture toughness: CT, DCB, SENT, and RT. These specimens provide a large range of $\mathrm{T}_{\mathrm{ef}}$ stresses from negative to positive values. We note that the DCB specimen exhibits only positive values of $\mathrm{T}$ stress. The same kind of specimens have different ligament sizes and thus exhibit different $\mathrm{T}_{\mathrm{ef}}$ values. Effective distance has been plotted versus effective $\mathrm{T}$ stress, according to the specimen type and ligament size (Fig. 23). We note that $\mathrm{X}_{\mathrm{ef}}$ increases when the constraint increases from negative to positive values. Effective distance is therefore not intrinsic to material but sensitive to constraint through stress distribution.

\section{CONCLUSION}

Most of the problems of transferability in fracture toughness can be treated with the help of a constraint parameter. However the scale effect always needs to be treated by a characteristic length and the loading mode cannot be treated by a two-parameter approach if the defect tip 
stress distribution is not homothetic. In this case, a stress gradient approach is preferred. This leads to the conclusion that a universal parameter of fracture toughness transferability is not available. The actual solution is to choose the ad hoc parameter according to the problems and after checking whether the conditions of validity are fulfilled.

If a constraint parameter is required, a question arises about the choice among the different possibilities ( $T, Q, \beta, \mathrm{L} \mathrm{A}_{2}, \mathrm{~A}_{\mathrm{P}}, \varphi$, and so on).

In order to answer this question, Hohe et al. [47] tested four 2-parameter approaches, the K-T stress-, J-Q-, J-A2-, and J- $\beta$-concepts. They found that all four approaches are able to characterize the local constraint situation of the different specimen geometry types considered. In a master curve analysis, they showed that the master curve reference temperature depends approximately linearly on the respective secondary fracture parameters of all four concepts.

Regarding the literature, the $\mathrm{T}$ stress is most often used. Compendia of $\mathrm{T}$ stress solutions and experimental and numerical methods are available and numerous results have been published. This is probably the reason for its popularity. However, from its definition, $\mathrm{T}$ is restricted to elastic behaviour, but it is interesting to note that the results of [47] have been extended to the elastic-plastic situation.

The Q stress can be used in elastic and elastic plastic conditions for fracture but its use is limited by the validity conditions. The stress distribution is nearly homothetic if only one geometrical or loading mode is modified. If two or more parameters are changing at the same time, this condition is not fulfilled and it is necessary to use a three-parameter approach including the stress gradient.

To overcome these difficulties, the trend is to use a three-parameter approach by adding the gradient or the third term of William's expansion $\mathrm{A}_{3}$.

But this approach seems difficult to introduce in design codes and standards. The actual method, which consists of comparing the results of the design computing with a material characteristic, is not easily modify. Eventually, some empirical corrections are proposed. Two- or three-parameter approaches need additional computing and additional data and therefore have additional costs. Geometrical and loading mode effects are therefore incorporated in the design factor as corrections.

\section{REFERENCES}

[1] Sinclair G. B \& Chambers A.E "Strength size effects and fracture mechanics: what does the physical evidence say?” Engineering Fracture Mechanics, Vol 26,N²,: 279-310(1987).

[2] Morrisson J.L.M (1939) "The yield of mild steel with particular reference of the effect of size of specimen", Proc.of the Inst.of Mech.Eng., 142,1,:193-223.

[3] Carpinteri A." Decrease of apparent tensile and bending strength with specimen size: Two different explanations based on fracture mechanics", International Journal of Solids and Structures, Vol 25, N4 :407-429, (1989).

[4] Carpinteri A. "Scaling laws and renormalisation groups for strength and toughness of disordered materials”, Int.J. Solids Structures, 31, N³ :291-302, (1994). 
[5] Bazan Z.P“ Scaling law of quasi brittle fracture asymptotic analysis, International Journal of Fracture ,83:19-40, (1997).

[6] Chechulin B.B'Influence of specimen size on the characteristic mechanical value of plastic fracture “,(in Russian), Zhur. Tekh.Fiz, 24 :1093-1100,(1954).

[7] Mouwakeh M. Pluvinage G. and Masri S. "Failure of water pipes containing surface cracks using limit analysis notions". Res. J. of Aleppo Univ. Engineering Science Series, No. 63, (2011).

[8] Henry B. S., and Luxmore A. R. "The stress triaxiality constraint and the Q-value as a ductile fracture parameter” Engineering Fracture Mechanics, 57 : 375-390, (1997).

[9] RuggieriC. Gao X. and Dodds R. H "Transferability of elastic-plastic fracture toughness using the Weibull stress approach: Significance of parameter calibration", Engineering Fracture Mechanics 67 : 101-117, (2000).

[10] Hadj Meliani, M., Matvienko, Y. G., Pluvinage, G. "Two-parameter fracture criterion $\left(\mathrm{K}_{\rho, \chi}-\mathrm{T}_{\mathrm{ef}, \mathrm{c}}\right)$ based on notch fracture mechanics", Inter. Journal of Fracture 167: 173-182 (2011).

[11] Nikishkov G.P"An algorithm and computer program for the three-term asymptotic expansion of elastic-plastic crack tip stress and displacement field"Engng Frac Mech; 50: 65-83, (1995).

[12] Aifantis E.C "The physics of plastic deformation" International Journal of Plasticity”, Vol.3 :212-247, (1987).

[13] Brandt A. "Calcul des pièces à la fatigue par la méthode du gradient “, Editor CETIM, (In French),(1980).

[14] Adib-Ramezani H. Jeong J. "Advanced volumetric method for fatigue life prediction using stress gradient effects at notch roots", Computational Materials Science, 39 : 649 663,(2007).

[15] Matic P. Kirby G.C and Jolles M.I "The relation of tensile specimen size and geometry effects to constitutive parameters for ductile materials", Proc. Roy.Soc.,London, A, 417: 309333,(1988).

[16] Williams M.L" On the stress distribution at the base of stationary Crack", ASME J Appl Mech, 24:109-114,(1957).

[17] Larsson S.G and Carlsson, A. J "Influence of non-singular stress terms and specimen geometry on small-scale yielding at crack tips in elastic-plastic materials", $J$ Mech Phys Solids 1 (21), : 263-77 (1973).

[18] Hutchinson J. W, "Singular Behavior at the End of a Tensile Crack in a Hardening Material", Journal of Mechanics and Physics of Solids,vol.16 : 13-31 (1968).

[19]O'Dowd N.P and Shih C.F "Family of Crack-Tip Fields Characterized by a Triaxiality Parameter: Part I - Structure of Fields", Journal of the Mechanics and Physics of Solids, Vol. 39 : 989-1015,(1991).

[20] O'Dowd N.P. and Shih C.F "Family of Crack-Tip Fields Characterized by a Triaxiality Parameter: Part II - Fracture Applications", Journal of the Mechanics and Physics of Solids, Vol. 40 : 939-963, (1992).

[21] Yang. B, Ravichandar. K "Evaluation of T stress by stress difference method". Engng Fract Mech,; 64 :589-605,(2001). 
[22] Chao Y.J, Liu .S Broviak B.J "Brittle fracture: variation of fracture toughness with constraint and crack curving under mode I conditions." Exp Mech ;41 :232-41, (2001).

[25] Ayatolahi M.R Pavier M.J, Smith. D.J. "Mode I cracks subjected to large T stress". Int J Fract;117:159-74,(2002).

[26] Hadj Meliani M , Azari Z. Pluvinage G., Matvienko Yu.G. " The Effective T-stress Estimation and Crack Paths Emanating from U-notches" Engineering Fracture Mechanics, Volume 77, Issue 11, July : 1682-1692,(2010).

[27] Maleski M.J , Kirugulige M.S and Tippur H.V, "A Method for Measuring Mode I Crack Tip Constraint Under Static and Dynamic Loading Conditions ”. Society for Experimental Mechanics. Vol. 44, No. 5, October, (2004).

[28] Hadj Meliani M , Matvienko Y. G., Pluvinage G. "Two-parameter fracture criterion $\left(\mathrm{K}_{\rho, \chi}-\mathrm{T}_{\mathrm{ef}, \mathrm{c}}\right)$ based on notch fracture mechanics", International Journal of Fracture, 167: 173182,(2011).

[29] Dodds R, Ruggieri C and Koppenhefer K. "3D Constraint effects on models for transferrability of cleavage fracture toughness”. ASTM 1321: 179-197, (1997).

[30] Rice J.R and Tracey D.M Journal of Mechanics and Physics of Solids, 26 163-186, (1969).

[31] Kaechele L.E and Tetelman A.S , Acta Metall, vol. 17, : 463-475 (1969).

[32] Akourri.O, Elayachi.I, Pluvinage.G "Stress Triaxiality as Fracture Toughness Transferability Parameter for Notched Specimens International". Review of Mechanical Engineering (I.RE.M.E.), Vol. 1, N6, November, (2007).

[33] Nikishkov G.P. "An algorithm and a computer program for the three-term asymptotic expansion of elastic-plastic crack tip stress and displacement fields" Engineering Fracture Mechanics, Volume 50, Issue 1, January, : 65-83,(1995).

[34] Chao Y.J. and Zhang X. "Constraint effect in brittle fracture". 27th National Symposium on Fatigue and fracture. ASTM STP 1296. R.S. Piascik. J.C. Newman. Jr. and D.E. Dowling. Eds. American Society for Testing and Materials. Philadelphia: 41-60, (1997).

[35] Chao Y.J, Reuter W.G.” Fracture of surface cracks under bending loads. In: Underwood JH, MacDonald B, Mitchell M(eds) Fatigue and fracture mechanics, vol 28,ASTMSTP 1321. American Society for Testing and Materials, Philadelphia: 214-242, (1997).

[36] Chao Y.J Liu S and Broviak B.J . "Brittle fracture: variation of fracture toughness with constraint and crack curving under mode I conditions". Experimental Mechanics, 41(3) :232241(2001).

[37] Mostafavi M, Smith D.J, Pavier M.J. “A micromechanical fracture criterion accounting for in-plane and out-of-plane constraint”. Comput Mater Sci ;50 :2759-70,(2011).

[38] Yang. J , Wang. G.Z , Xuan F.Z, Tu. S.T. "Unified correlation of in-plane and out-ofplane constraint with fracture resistance of a dissimilar metal welded joint". Engineering Fracture Mechanics, 115 : 296-307, (2014).

[39] Sherry A.H, France C.C and. Goldthorpe M.R. "Compendium of T-stress solution for two and three dimensional cracked geometries". Fatigue and Fracture of Engineering Materials and Structures, vol. 18 : 141-155, (1995).

[40] Hadj Meliani.M, Azari .Z, Pluvinage.G, Matvienko. Yu.G. " The Effective T-stress Estimation and Crack Paths Emanating from U-notches" Engineering Fracture Mechanics, 77? : 1682-1692, (2010). 
[41] Enyang Wang, Wenxing Zhou, Guowu Shen. “Three-dimensional finite element analysis of crack-tip fields of clamped single-edge tension specimens - Part II: Crack-tip constraints For any pressure values and pipe diameter, Engineering Fracture Mechanics, $116 ?: 144-157 .(2014)$.

[42] Eisele U.and Roos E. "Evaluation of different fracture-mechanical J-integral initiation values with regard to their usability in the safety assessment of components". Nuclear Engineering and Design, Vo1.130:237-247,(1990).

[43] Dlouhy. I, Holzmann. M , Chlup. Z . "Fracture resistance of cast ferritic C.Mn steel for Container of spent Nuclear fuel." in Transferability of fracture Mechanical Characteristics Edito Dlouhy, NATO Sciences Series : 47-64. (2001);

[44] Hadj Meliani M, Pluvinage G, Matvienko Yu.G. "Two-parameter fracture criterion (Kp,c-Tef,c) based on notch fracture mechanics Int J Fract Volume: 167, Issue: 2,: 173 182, (2011).

[45] Wallin. K. "Quantifying T-stress controlled constraint by the master curve transition temperature T0. Engng Frac Mech, 68: 303-28, (2001).

[46] Wallin.K. "Structural integrity assessment aspects of the Master Curve methodology", Engineering Fracture Mechanics, 77: 285-292, (2010).

[47] Hohe J. Hebel 1, FriedmannV, Siegele D."Probabilistic failure assessment of ferritic steels using the master curve approach including constraint effects" Engineering Fracture Mechanics, 74 :1274-1292, (2007).

[48] Coseru A. Capelle J. and Pluvinage G."On the use of charpy transition temperature as reference temperature for the choice of a pipe steel". Engineering Failure Analysis Volume 37, February: 110-119,(2014).

[49] G. Pluvinage , M. Ben Amara J. Capelle , Z. Azari. Role of constraint on the shift of ductile brittle transition temperature of subsize charpy specimens. To appear Journal of Fatigue and Fracture in Engineering Materials

[50] Akourri O. Louah M. Kifani A. Gilgert J. Pluvinage G.

"The effect of notch radius on fracture toughness $\mathrm{J}_{1 \mathrm{c}}$ " Engineering Fracture Mechanics, $\mathrm{N}^{\circ} 65$ :491-505,(2000).

[51] Cotterell B. "Slightly curved or kinked cracks", International Journal of Fracture, Vol.16, No. 2, April, 155-169, (1980).

[52] Erdogan F. and Sih, G.C.”On the crack extension in plates under loading and transverse shear". Transaction of the ASME. J.Basic Eng, 85 : 519-527, (1963).

[53] Chao Y. J. Liu S.and Brovia B. J. "Brittle Fracture: Variation of Fracture Toughness with Constraint and Crack Curving under Mode I Conditions", Experimental Mechanics, Vol.41, Issue 3, 232-241, (2001).

[54] Zhao J.\& Guo W. "Three-parameter K-T-Tz characterization of the crack-tip fields"in compact-tension-shear specimens", Engineering Fracture Mechanics, 92 : 72-88, (2012).

[55]Aifantis E.C "The physics of plastic deformation", International Journal of Plasticity",Vol.3212-247, (1987).

[56] Malmberg .T minutes of the task 5 group meeting, Joint research centre, EU project.FI4S-CT96-0024,(1998) .

[57 ] W. Yao, Stress intensity approach for predicting fatigue life, International Journal of Fatigue, 1993;15:243. 
